\title{
Doğu Anadolu Bölgesi’nde Thornthwaite tipi aylık su bilançosu analizi
}

\author{
Emre TOPÇU* \\ Kafkas Üniversitesi, Inşaat Mühendisliği, Kars \\ (ORCID: 0000-0003-0728-7035)
}

\begin{abstract}
Öz
Kurak ve yarı kurak bölgelerdeki su kaynakları, iklim değişikliği ve artan su taleplerinden büyük ölçüde etkilenmektedir. Aylık yüzeysel akış hidrolojik çalışmalarda en önemli faktörlerden biridir. Aylık ortalama yüzeysel akış, havzaların bölgesel aylık su dengesi modelleri ile tahmin edilebilmektedir. Bu çalışmada Türkiye'nin Doğu Anadolu Bölgesi'nde bulunan 13 meteoroloji istasyonunun 2010-2018 yılları arasındaki aylık toplam yağış ve aylık ortalama sıcaklık verileri kullanılarak Thornthwaite tipi aylık su bilançosunun hesap edilmesi amaçlanmıştır. Potansiyel evapotranspirasyon Hamon metodu kullanılarak elde edilmiştir. Su bilançosu parametre sonuçları her istasyon için ayrı olarak verilmiştir. Sonuçlara göre Elazı̆̆g, Erzincan, Iğdır ve Malatya istasyonlarında su fazlası ve yüzeysel akış yoktur. Su açığının en fazla olduğu il Malatya istasyonu olarak tespit edilirken yüzeysel akışın en fazla olduğu istasyon Bitlis istasyonu olarak tespit edilmiştir. Çalışma alanındaki sulak alanların korunması için kurak bölgelerin su kaynakları yönetiminde yeterli su talebini belirlemek için Thornthwaite tipi aylık su bilançosu modeli kullanılabilir.
\end{abstract}

Anahtar kelimeler: Evaporasyon, Thornthwaite, Su Bilançosu, Doğu Anadolu Bölgesi.

\section{An analysis of Thornthwaite type monthly water balance in Eastern Anatolia Region}

\begin{abstract}
Water resources in arid and semi-arid regions are greatly affected by climate change and increasing water demands. Monthly runoff is one of the most important factors in hydrological studies. The monthly average runoff can be estimated by regional monthly water balance models. In this study, it is aimed to calculate the Thornthwaite type monthly water balance at 13 meteorological stations located in the Eastern Anatolia Region of Turkey by using monthly total precipitation and monthly mean temperature values in 2010-2018 period. Potential evapotranspiration was obtained using the Hamon method. The results of the water balance tables are given for

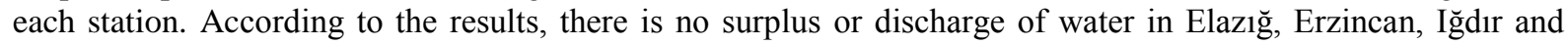
Malatya stations. Water deficit is at the most Malatya station. Bitlis station is the station with the highest runoff. The Thornthwaite type monthly water balance model can be used to determine the sufficient water demand for the management of arid areas in water resources for protection of wetlands in the study area.
\end{abstract}

Keywords: Evaporation, Thornthwaite, Water Balance, Eastern Anatolia Region.

\section{Giriş}

Dünya'daki önemli iklim değişikliği etkilerinin çoğu, yağış ve su mevcudiyeti ile ilişkilidir. İklim değişikliği, özellikle sıcaklığın buharlaşmaya etkisi ve artan yağış değişkenliği nedeniyle göller, nehir havzaları ve suyolları ile ilgili kanıtlarda ortaya çıkacaktır. Azalan yağış ve su kıtlığı, tarımsal üretim ve gida güvenliği üzerinde önemli olumsuz etkiye sahip olacaktır [1]. Bir su bilançosu, bir proje alanına giren ve çıkan tüm suyun muhasebesidir. Bu alan bir sulak alan, göl veya ilgi çekici herhangi bir nokta olabilir. Bir bölgenin ekonomik olarak kalkınması, doğal su kaynağını değiştirebilir ve özellikle yakındaki göller veya sulak alanlar varsa, bu alanları ciddi şekilde etkileyebilir. Aynı zamanda göller,

*Sorumlu yazar: emretopcu01@gmail.com

Geliş Tarihi: 09.01.2019, Kabul Tarihi: 09.05.2019 
bulundukları yerin hidrolojik çevirimi ile yakından ilgilidir ve iklim değişikliklerinin hassas belirteçleridir [2]. Bu etkilerin büyüklüğünü belirlemek ve olası azaltma eylemlerini değerlendirmek için bir su bilançosu gereklidir. Bir su bilançosu, hidrolojik döngünün çeşitli bileşenlerini tanımlar. Su bilançosu tipik olarak şunları içermektedir: Yağış (Y), Buharlaşma (B), Evapotranspirasyon (ET), Yüzeysel akış (YA), Yeraltı suyu akışı (YSA). Su bilançosu bu bileşenlerle ilgili bir denklem olarak ifade edilir $(\triangle S=Y-B-E T \pm Y A \pm Y S A)$. Örneğin, denklemin sağ tarafindaki ifade pozitif ise, depolama artacak ve ilgilenilen alandaki su seviyesi artacaktır. Depodaki pozitif bir değişim genellikle artı değer (surplus) olarak adlandırılırken, depodaki bir azalma ise açı (deficit) ile ifade edilir. Depodaki değişiklik genellikle mm cinsinden açıklanmaktadır.

Su bilançosu denkleminin ilk üç terimi, yağış, buharlaşma ve evapotranspirasyon büyük ölçüde kalkınmadan etkilenmeyen doğal süreçlerdir. Ancak, arazi kullanımındaki değişiklikler yüzeysel akışı ve yeraltı suyu akışını önemli ölçüde etkileyebilir. Örneğin, ticari gelişim sulak alanlara giren yüzey akışını engelleyebilir ve yağmur suyu kontrol havuzuna yönlendirebilir. Bu yağmur suyu havzası, buharlaşana veya çıkış akımına bırakana kadar suyu tutabilir. Her iki durumda da, sulak alan, gelişimden önce mevcut olan yüzeysel akıştan mahrumdur. Benzer şekilde, su kaynağı kuyuları yeraltı suyu seviyelerini kalıcı olarak düşürebilir ve yüzeysel akış yönlerini değiştirebilir.

Su bilançosu belirli bir süre için hesaplanır. Kalıcı projeler günlük veya aylık veriler kullanılarak değerlendirilebilir, elde edilen net fazla veya açık, mevsimsel veya yıllık değer olarak ifade edilir. Bakım için bir rezervuarın düşürülmesi gibi kısa vadeli projeler, saatlik veya haftalık veriler kullanılarak değerlendirilebilir ve sonuçları aylık veya mevsimsel olarak ifade edilebilir. Bir su bilançosu, çeşitli koşullar için hesaplanmalıdır.

Su bilançosu hesaplamanın en zor kısmı net fazlalığın veya açı̆̆ın doğru bir şekilde tahmin edilmesine izin veren verileri bulmaktır. Eğer proje esas olarak yüzeysel akışa bağlıysa, yılların normal, normalin altında ve normal yağışların üzerinde olduğunu tanımlayabilir ve bu bilgiyi bu üç iklim koşulunda yüzey akışını belirlemek için kullanabilir. Ancak, proje alanı yer altı suyu akışına bağlıysa, bir dizi koşul için ideal olarak yer altı suyu akış verileri kullanılmalıdır. Bir alanın yıllık su bilançosu yıl boyunca suyun yüzeysel akışını -bitki örtüsü türünü ve bolluğunu belirler, ağaçlar için elverişli ve elverişsiz koşulları gösterir. Diğer bitki örtüsü ve sulama talebi için bir vekil olarak hizmet edebilir. Bir de, su kaynăğ, toprak suyu depolaması ve su talebinin doğrusal olmayan bir kombinasyonunu temsil eder. Yağıı̧ miktarı, kar olarak düşen oran ve karın erimesi bir sahadaki su kaynağını belirler [3]. Bir bölge için su bilançosu diyagramı Şekil 1'de görülmektedir.

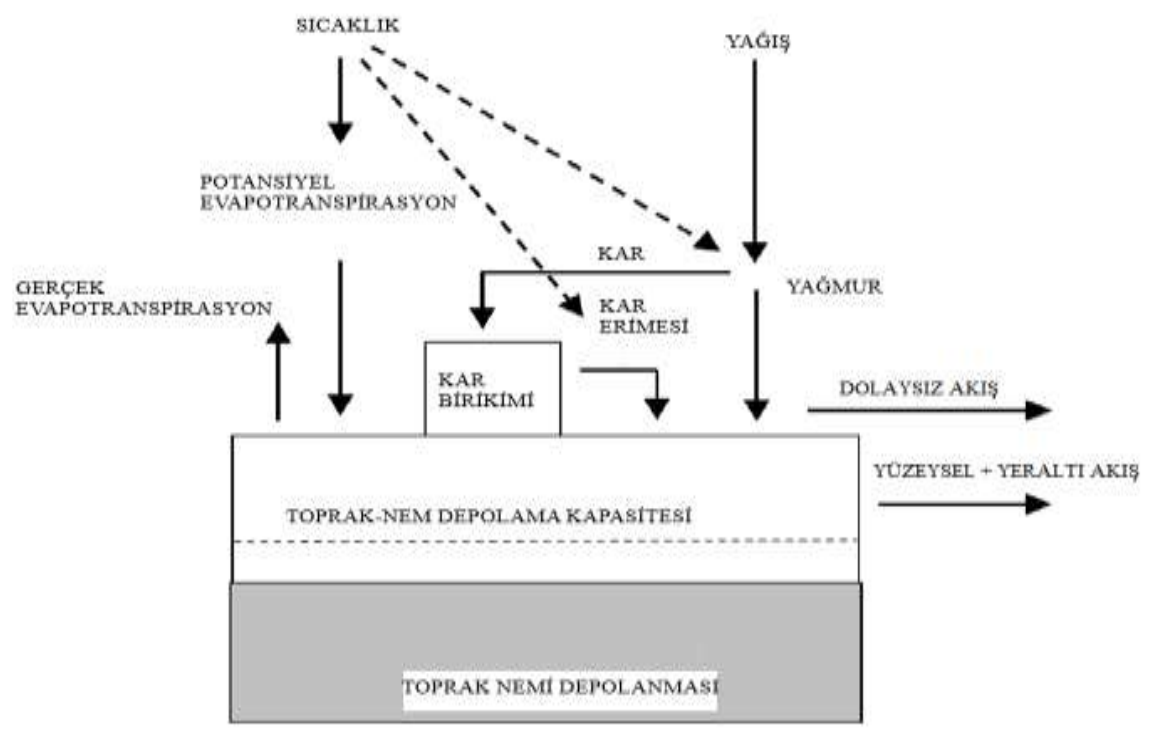

Şekil 1. Su bilançosu diyagramı [4]

Sıcaklık ve yağışa dayalı su bilançosu modelleri Thornthwaite ve Mather [5] tarafından geliştirilmiştir. Thornthwaite yöntemi rüzgâr hızı, bulutluluk ve radyasyon gibi parametreleri kullanmasa da en iyi sonucu vermektedir [6]. 
Bu çalışmada Türkiye'nin 7 bölgesinden biri olan Doğu Anadolu Bölgesi'nde Thornthwaite tipi aylık su bilançosu hesaplanması amaçlanmıştır. Su bilançosu diyagramında yer alan aylık ortalama sıcaklığın ve aylık toplam yağışın tüm istasyonlar için eksiksiz olduğu 2010-2018 yılları arasında hesap yapılmıştır. Doğu Anadolu Bölgesi’nde yer alan toplamda 13 ilin yağış ve sıcaklık verileri kullanılmıştır.

\section{Materyal ve Metot}

\subsection{Materyal}

Çalışma alanı olarak Türkiye'nin doğusunu kaplayan Doğu Anadolu Bölgesi seçilmiştir. Doğu Anadolu Bölgesi'nin Türkiye'deki konumu Şekil 2'de görülmektedir [7]. Toplamda 150.210 km2'lik bir alanı kaplamaktadır. Türkiye'de kış şartlarının en ağır geçtiği bölgedir. Su bilançosunun temel parametrelerinden olan kar örtüsü bu bölgede tüm kış mevsimi boyunca bulunmaktadır.

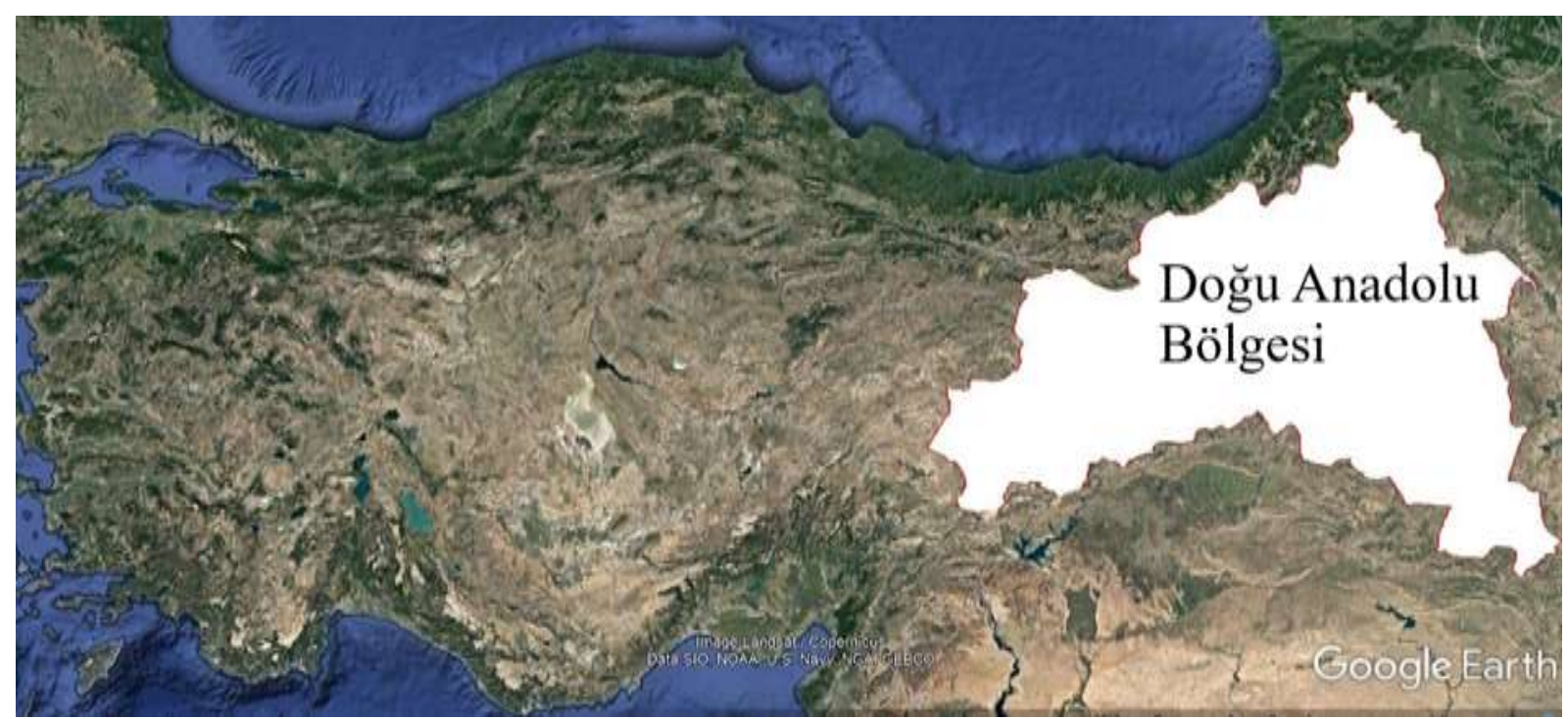

Şekil 2. Doğu Anadolu Bölgesi’nin Türkiye'deki konumu [7]

Doğu Anadolu Bölgesi'ndeki 13 ilin il merkezlerindeki meteoroloji istasyonları kullanılarak analiz gerçekleştirilmiştir. Çalışmada kullanılan istasyonlar, rakımları, enlemleri ve boylamları Tablo 1 'de verilmektedir. Meteoroloji istasyonlarının konumu ise Şekil 3'te verilmektedir.

Tablo 1. Çalışmada kullanılan istasyonların rakım, enlem ve boylamları

\begin{tabular}{|c|c|c|c|c|}
\hline İstasyon No & İsim & Rakım (m) & Enlem (K) & Boylam (D) \\
\hline 17046 & Ardahan & 1827 & 41.1061 & 42.7055 \\
\hline 17094 & Erzincan & 1216 & 39.7523 & 39.4868 \\
\hline 17097 & Kars & 1777 & 40.6042 & 43.1073 \\
\hline 17099 & Ağr1 & 1646 & 39.7253 & 43.0522 \\
\hline 17100 & Ĭğır & 856 & 39.9227 & 44.0523 \\
\hline 17165 & Tunceli & 981 & 39.1058 & 39.5408 \\
\hline 17172 & Van & 1675 & 38.4693 & 43.346 \\
\hline 17199 & Malatya & 950 & 38.3367 & 38.2173 \\
\hline 17201 & Elazı̆ & 989 & 38.6443 & 39.2561 \\
\hline 17203 & Bingöl & 1139 & 38.8847 & 40.5007 \\
\hline 17204 & Muş & 1322 & 38.7509 & 41.5023 \\
\hline 17208 & Bitlis & 1785 & 38.475 & 42.1625 \\
\hline 17285 & Hakkâri & 1727 & 37.5745 & 43.7388 \\
\hline
\end{tabular}




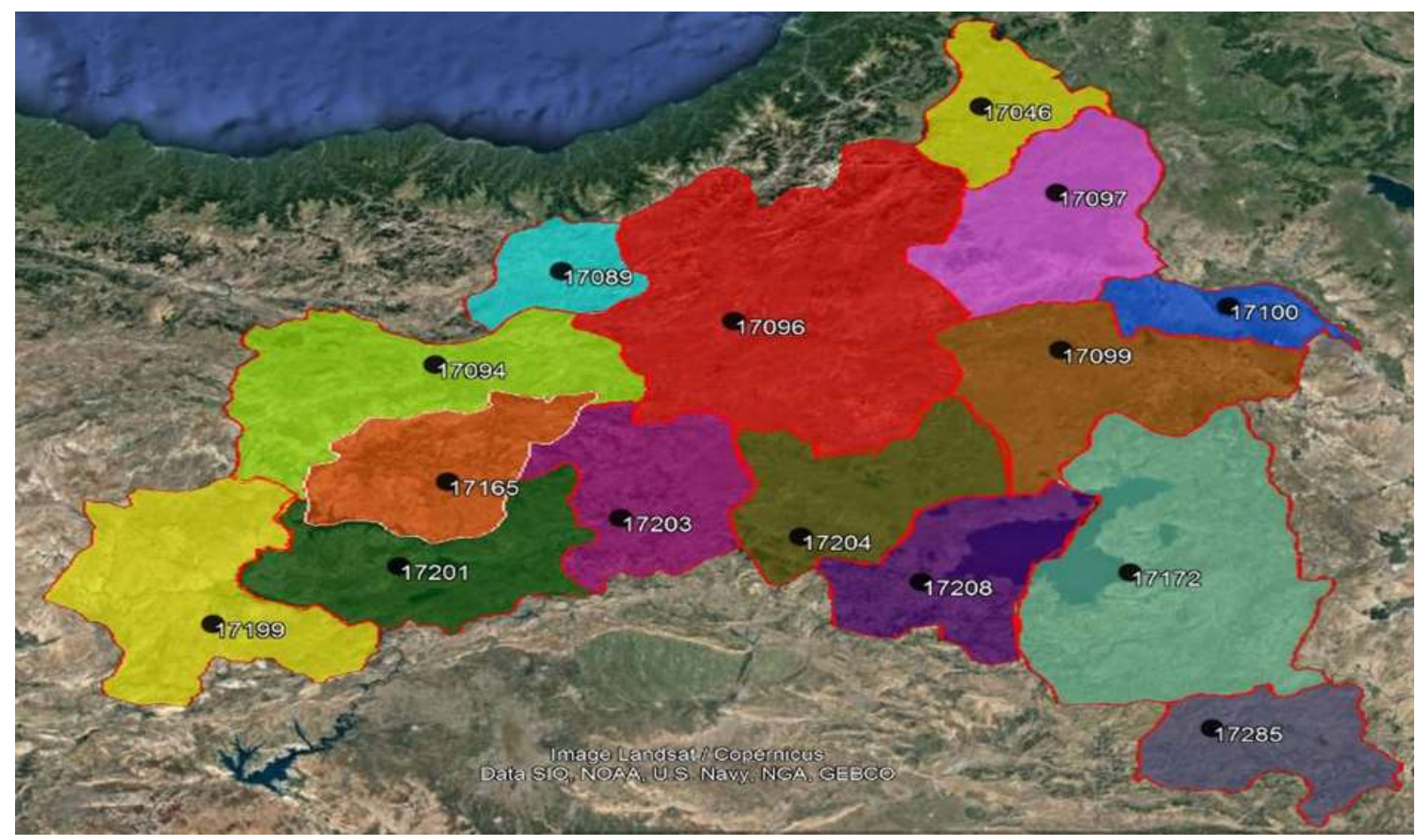

Şekil 3. Meteoroloji istasyonlarının konumları

\subsection{Metot}

Thornthwaite tipi aylık su bilançosu modelleri, yağış alanının kararlı durumdaki mevsimsel (iklimsel ortalama) veya sürekli değerlerini veya bölgesel su girdisini, kar örtüsünü, toprak nemini ve evapotranspirasyonu simüle etmek için kullanılan kavramsal modellerdir. Bu tip modeller için veri girdisi olarak, ilgili bölgeyi temsil eden yağış $\left(\mathrm{P}_{\mathrm{m}}, \mathrm{m}: 1,2,3, \ldots, 12\right)$ ve sıcaklık $\left(\mathrm{T}_{\mathrm{m}}\right)$ parametreleri kullanılmaktadır. $\mathrm{Bu}$ parametreler kararlı durumdaki (steady-state) uygulamalarda aylık iklimsel ortalamalardır. Bu tarz modeller tipik olarak tek bir parametreye sahiptirler ve o da toprağın toprak-su

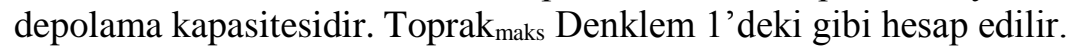

Toprak $_{\text {maks }}=\theta_{a k} \cdot Z_{k b}$

Burada $\theta_{a k}$ alan kapasitesini, $Z_{k b}$ kök bölgesinin düşey derinliğini göstermektedir. Toprak $k_{m a k s}$ bu çalışmada $100 \mathrm{~mm}$ olarak varsayılmıştır. Çalışmaya göre Toprak ${ }_{\text {maks }}$ ayrıca belirlenebilir.

Aylık yağış Yağmur $r_{m}$ ve Kar ${ }_{m}$ olarak ikiye bölünür (Denklem 2 ve Denklem 3);

Yağmur $_{\mathrm{m}}=\mathrm{F}_{\mathrm{m}} \cdot \mathrm{P}_{\mathrm{m}}$

$\operatorname{Kar}_{m}=\left(1-F_{m}\right) \cdot P_{m}$

Burada $F_{m}$ erime faktörünü göstermektedir. Erime faktörünü $\left(F_{m}\right)$ basitçe hesaplayan yaklaşım Denklem 4 'te verilmektedir.

$\mathrm{F}_{\mathrm{m}}=0, \mathrm{~T}_{\mathrm{m}} \leq 0{ }^{0} \mathrm{C}$

$\mathrm{F}_{\mathrm{m}}=0.167 . \mathrm{T}_{\mathrm{m}}, 0{ }^{\circ} \mathrm{C}<\mathrm{T}_{\mathrm{m}}<6{ }^{\circ} \mathrm{C}$;

$\mathrm{F}_{\mathrm{m}}=1, \mathrm{~T}_{\mathrm{m}} \geq 6^{\circ} \mathrm{C}$

Erime faktörü ayrıca sıcaklık-gösterge kar erimesi modelinde de aylık kar erimesini belirlemek için kullanilır (Denklem 5);

Erime $_{\mathrm{m}}=\mathrm{F}_{\mathrm{m}} \cdot\left(\mathrm{KÖ}_{\mathrm{m}-1}+\mathrm{Kar}_{\mathrm{m}}\right)$ 
Burada KÖ kar örtüsünü, $\mathrm{KÖ}$ m-1 ise m-1 ayının sonundaki kar örtüsünün su eşdeğerini göstermektedir. M ayının sonundaki kar örtüsü Denklem 6'daki gibi hesaplanır,

$\mathrm{KÖ}=\left(1-F_{m}\right)^{2} \cdot P_{m}+\left(1-F_{m}\right) \cdot K \ddot{O}_{m-1}$

O halde aylık su girdisi (veya kaynağı, water input) Denklem 7'deki gibi elde edilir:

$\mathrm{W}_{\mathrm{m}}=$ Yağmur $_{\mathrm{m}}+$ Erime $_{\mathrm{m}}$

Eğer su girdisi potansiyel evapotranspirasyonu aşarsa $\left(\mathrm{W}_{\mathrm{m}}-\mathrm{PET}_{\mathrm{m}} \geq 0\right)$, evapotranspirasyon potansiyel oranda devam eder ve oluşan fazlalık toprak suyunu yeniden doldurur. Fakat toprak zaten su tutma kapasitesine ulaştıysa, toprak nemi sabit kalır ve fazlalık yüzeysel akışa dönüşür. Potansiyel evapotranspirasyon Hamon [8] denklemi ile hesap edilir (Denklem 8),

$P E T_{m}=29.8 *$ Günler $* G U * \frac{e_{a}\left(T_{a}\right)}{T_{a}+273.2}$

Burada Günler ay içindeki gün sayısını, GU ay için ortalama gün uzunluğunu ve $e_{a}\left(T_{a}\right), T_{a}$ ortalama sıcaklığındaki doygun buhar basıncını göstermektedir. $e_{a}\left(T_{a}\right)$ Denklem 9' daki gibi hesaplanır,

$e_{a}=0.611 * \exp \left(\frac{17.3 * T_{a}}{T_{a}+237.3}\right)$

Potansiyel evapotranspirasyon, sıcaklığın üssel artan fonksiyonu olarak modellenmiştir. Örneğin potansiyel evapotranspirasyonun $20{ }^{\circ} \mathrm{C}^{\prime} \mathrm{den} 22{ }^{\circ} \mathrm{C}^{\prime}$ ye yükselmesi, $10{ }^{\circ} \mathrm{C}$ 'den $12{ }^{0} \mathrm{C}^{\prime}$ ye yükselmeye göre çok daha fazladır.

Gün uzunluğu olan GU (saat), Denklem 10'daki gibi ifade edilir [9].

$G U_{m}=\frac{2 * \cos ^{-1}\left[-\tan \left(\delta_{m}\right) * \tan (\Lambda)\right]}{\omega}$

Burada $\delta_{m}$ ayın 15. gününde akşamüzeri güneşe göre hesaplanan eğim açısını, $\Lambda$ enlemi, $\omega$ ise dünyanın dönüşünün açısal hızını göstermektedir (0.2618 radyan/saat).

Toprak su bilançosu Denklem 11'deki gibi elde edilir.

Toprak $_{m}=\operatorname{minimum}\left\{\right.$ Toprak $_{\text {maks }},\left[\left(W_{m}-\right.\right.$ PET $\left._{m}\right)+$ Toprak $\left.\left._{m-1}\right]\right\}$

Burada Toprak $k_{\text {maks }}$, toprak profilinin ilk 200 cm'sindeki toprak su tutma kapasitesini göstermektedir.

Eğer PET su girdisinden daha büyükse $\left(\mathrm{W}_{\mathrm{m}}<\mathrm{PET}_{\mathrm{m}}\right)$, evapotranspiration su girdisi + toprak su deposundan uzaklaşan kısıma eşit olur. Toprak kuru hale geldikçe toprak suyunun ayrışması daha zor bir hale gelir. Toprak su deposundan uzaklaşan kısım Denklem 12'deki gibi hesap edilir,

$\Delta_{\text {Toprak }}=$ Toprak $_{m-1}-$ Toprak $_{m}=$ Toprak $_{m-1} *\left[1-\exp \left(-\frac{\left(\text { PET }_{m}-W_{m}\right)}{\text { Toprak }_{\text {maks }}}\right)\right]$

$\mathrm{Bu}$ durumda gerçek evapotranspirasyon $\left(\mathrm{GET}_{\mathrm{m}}\right) \mathrm{PET}_{\mathrm{m}}$ 'in veya $\left(\Delta_{\text {Toprak }}+\mathrm{W}_{\mathrm{m}}\right)$ 'in daha küçügüne eşit olur. Açık ise $\mathrm{PET}_{\mathrm{m}}$ ile $\mathrm{GET}_{\mathrm{m}}$ arasındaki farktır.

\section{Bulgular ve Tartışma}

Çalışmanın bu bölümünde Thornthwaite tipi su bilançosu yöntemi ile hesap edilen su bilançosu bileşenlerinin yıllık döngüsü il il tablo ve grafik şeklinde verilmiştir. Bazı illerde sadece tablo olarak verilmesi tercih edilmiştir. Tablo 2'de genel olarak tüm istasyonların 2010-2018 yılları arasındaki su bilançosuna göre açık (deficit) ve fazla (surplus) değerleri görülmektedir. Tablo 2'ye göre yağışın en fazla olduğu istasyon yıllık $908 \mathrm{~mm}$ ortalama ile Bitlis istasyonudur. En az yağış ise Iğdır istasyonundadır. Potansiyel evapotranspirasyon en az Ardahan ilinde iken en yüksek Malatya ilindedir. Su bilançosuna göre açığın en fazla olduğu il Malatya'dır. Su fazlasının en çok olduğu il ise Bitlis'tir. Elazığ, Erzincan, Malatya ve Iğdır istasyonlarında ise yüzeysel akışa geçecek su fazlası yoktur. Şekil 
4'de ise bu değerlerin grafik hali yer almaktadır. İstasyonlarda Fazla olarak bulunan değerler yüzeysel akışa geçmiştir. Yüzeysel akış ve Fazla değerleri aynıdır.

Tablo 2. İstasyonların su bilançosuna göre Açık ve Fazla değerleri (mm/yıl)

\begin{tabular}{|c|c|c|c|c|c|}
\hline & Yă̆ış & PET & GET & Açık & Fazla \\
\hline Ă̆̊ı & 447 & 581 & 360 & 221 & 87 \\
\hline Ardahan & 542 & 469 & 445 & 24 & 97 \\
\hline Bingöl & 727 & 861 & 445 & 416 & 560 \\
\hline Bitlis & 908 & 628 & 348 & 280 & 0 \\
\hline Elazı̆̆ & 331 & 936 & 331 & 605 & 0 \\
\hline Erzincan & 341 & 796 & 341 & 455 & 368 \\
\hline Hakkari & 767 & 749 & 399 & 350 & 0 \\
\hline Ĭgdır & 233 & 870 & 233 & 637 & 15 \\
\hline Kars & 447 & 528 & 432 & 96 & 0 \\
\hline Malatya & 313 & 977 & 313 & 664 & 194 \\
\hline Muş & 581 & 761 & 387 & 374 & 244 \\
\hline Tunceli & 709 & 901 & 465 & 436 & 5 \\
\hline Van & 363 & 693 & 358 & 335 & \\
\hline
\end{tabular}

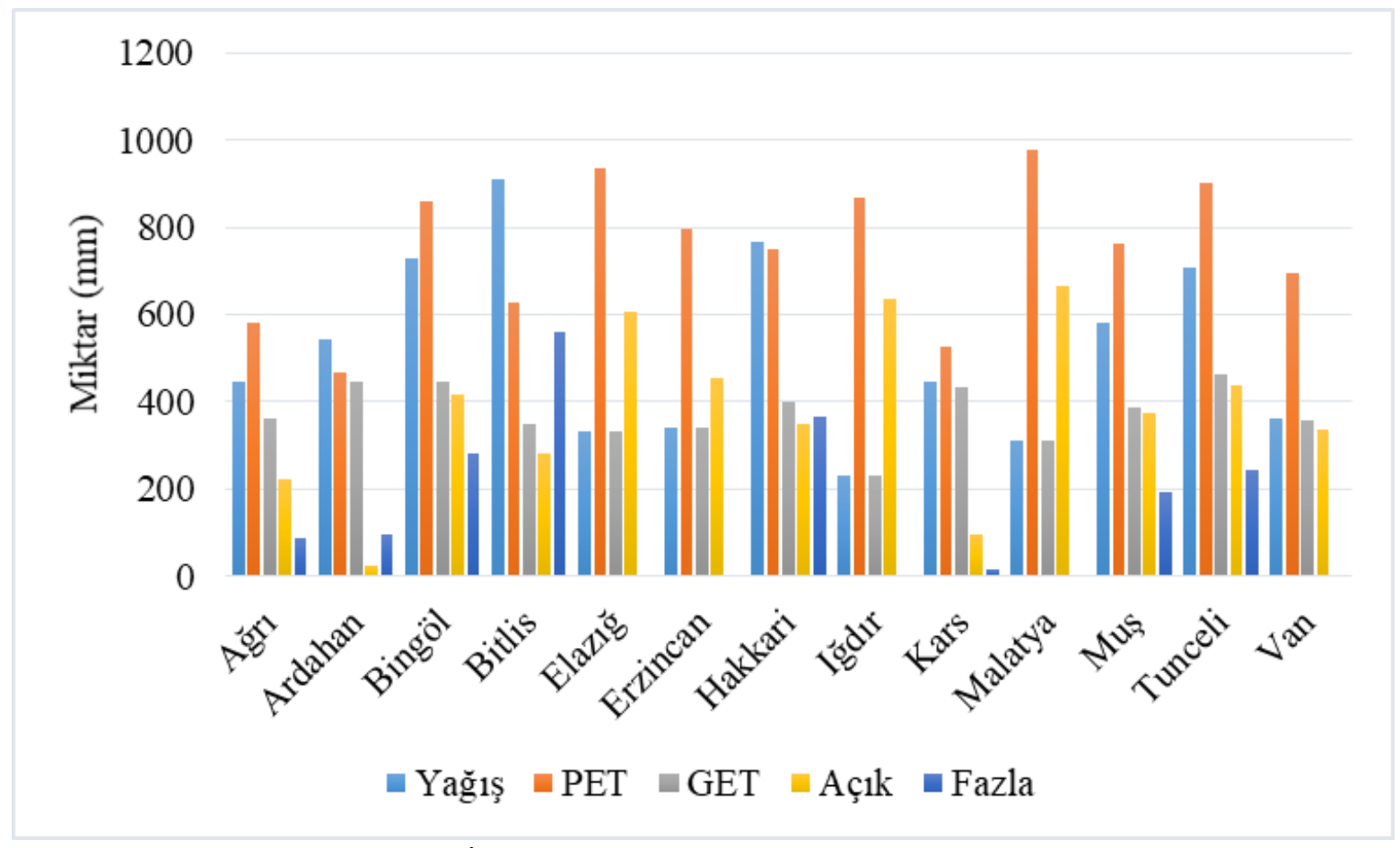

Şekil 4. İstasyonların su bilançosu parametre grafikleri

Thornthwaite tipi aylık su bilançosunda yer alan kısaltmalar ve açıklamaları Tablo 3 'te verilmektedir. 
Tablo 3. Tablolarda yer alan parametreler ve açıklamaları

\begin{tabular}{|c|l|}
\hline Parametre & Açıklama \\
\hline AY & Aylık Yağış \\
\hline AOS & Aylık Ort. Sıcaklık \\
\hline EF & Erime Faktörü \\
\hline YODY & Yağmur Olarak Düşen Yağış \\
\hline KODY & Kar Olarak Düşen Yağış \\
\hline KÖ & Kar Örtüsü \\
\hline KE & Kar Erimesi \\
\hline SG & Su Girdisi \\
\hline PET & Potansiyel Evapotranspirasyon \\
\hline NSG & Net Su Girdisi \\
\hline TN & Toprak Nemi \\
\hline ATN & Toprak Nemindeki Değişim \\
\hline GET & Gerçek Evapotranspirasyon \\
\hline B\&A & Beslenme\&Akış \\
\hline
\end{tabular}

\subsection{Ağrı İli Su Bilançosu Sonuçları}

Tablo 4'e göre Ağrı istasyonunda yıllık toplam yağış 447 mm'dir. Kar birikimi Kasım, Aralık, Ocak, Şubat ve Mart aylarında gerçekleşmektedir. Kar erimesinin neredeyse tamamı Nisan ayında gerçekleşmektedir. Hamon metoduna göre PET 581 mm'dir. En yüksek PET Temmuz ayında görülmüştür. $360 \mathrm{~mm}$ GET sonucunda $87 \mathrm{~mm}$ yüzeysel akış gerçekleşmiştir. Haziran ayından Ekim ayına kadar su eksiği görülür. Yağış PET’den küçüktür. Toprak nemi Nisan ve Mayıs aylarında maksimum kapasitededir. Ağrı İli Thornthwaite tipi aylık su bilançosu grafiği Şekil 5'te görülmektedir.

Tablo 4. Ağrı İli Thornthwaite tipi su bilançosu tablosu

\begin{tabular}{|c|c|c|c|c|c|c|c|c|c|c|c|c|c|}
\hline & \multicolumn{10}{|c|}{ AYLAR } \\
\hline Parametre & O & S & M & N & M & H & T & A & E & E & K & A & YII \\
\hline AY & 30 & 32 & 43 & 56 & 68 & 37 & 21 & 16 & 22 & 59 & 33 & 30 & 447 \\
\hline AOS & -8.2 & -7.6 & -0.1 & 7.6 & 12.2 & 17.0 & 21.9 & 22.5 & 17.3 & 9.6 & 1.5 & -6.5 & \\
\hline EF & 0.00 & 0.00 & 0.00 & 1.00 & 1.00 & 1.00 & 1.00 & 1.00 & 1.00 & 1.00 & 0.25 & 0.00 & \\
\hline YODY & 0 & 0 & 0 & 56 & 68 & 37 & 21 & 16 & 22 & 59 & 8 & 0 & 287 \\
\hline KODY & 30 & 32 & 43 & 0 & 0 & 0 & 0 & 0 & 0 & 0 & 25 & 30 & 160 \\
\hline KÖ & 79 & 111 & 154 & 0 & 0 & 0 & 0 & 0 & 0 & 0 & 19 & 49 & \\
\hline KE & 0 & 0 & 0 & 154 & 0 & 0 & 0 & 0 & 0 & 0 & 6 & 0 & 160 \\
\hline SG & 0 & 0 & 0 & 210 & 68 & 37 & 21 & 16 & 22 & 59 & 14 & 0 & 447 \\
\hline PET & 0 & 0 & 0 & 45 & 66 & 92 & 120 & 116 & 78 & 43 & 22 & 0 & 581 \\
\hline NSG & 0 & 0 & 0 & 165 & 3 & -55 & -99 & -100 & -56 & 16 & -8 & 0 & \\
\hline TN & 19 & 19 & 19 & 100 & 100 & 58 & 21 & 8 & 5 & 21 & 19 & 19 & \\
\hline ATN & 0 & 0 & 0 & 81 & 0 & -42 & -36 & -14 & -3 & 16 & -2 & 0 & \\
\hline GET & 0 & 0 & 0 & 45 & 66 & 79 & 57 & 29 & 25 & 43 & 16 & 0 & 360 \\
\hline B\&A & 0 & 0 & 0 & 85 & 3 & 0 & 0 & 0 & 0 & 0 & 0 & 0 & 87 \\
\hline
\end{tabular}

*AOS ${ }^{0} \mathrm{C}$, diğger parametreler $\mathrm{mm}$ cinsindendir. 


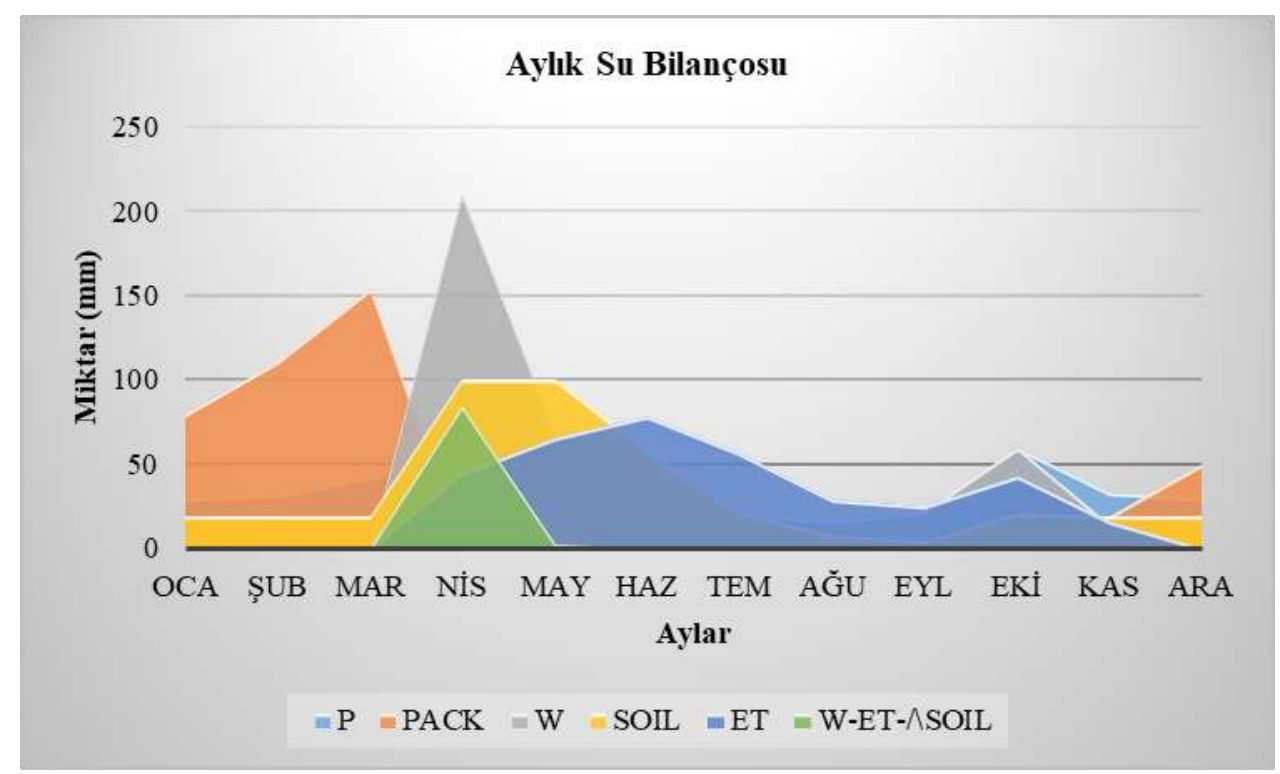

Şekil 5. Ağrı İli Thornthwaite tipi aylık su bilançosu grafiği

\subsection{Ardahan İli Su Bilançosu Sonuçları}

Tablo 5'e göre Ardahan istasyonu Türkiye'nin ve çalışma bölgesinin en soğuk şehridir. Yıllık $542 \mathrm{~mm}$ yağışa sahiptir. En yüksek PET Temmuz ayında görülmektedir. 2010-2018 yılları arasında ortalama 97 mm yüzeysel akış gerçekleşmiştir. Nisan, Mayıs, Haziran ve Temmuz aylarında toprak nemi maksimum kapasitededir. Kar örtüsü Kasım ayından Nisan ayına kadar görülür. Nisan ayında kar erimeleri başlar. Ağustos ve Ekim aylarında su eksiği ortaya çıkar. Ardahan İli Thornthwaite tipi aylık su bilançosu grafiği Şekil 6'da görülmektedir.

Tablo 5. Ardahan İli Thornthwaite tipi su bilançosu tablosu

\begin{tabular}{|c|c|c|c|c|c|c|c|c|c|c|c|c|c|}
\hline \multirow[b]{2}{*}{ Parametre } & \multicolumn{12}{|c|}{ AYLAR } & \multirow[b]{2}{*}{ Yil } \\
\hline & $\mathbf{O}$ & Ş & $\mathbf{M}$ & $\mathbf{N}$ & $\mathbf{M}$ & $\mathbf{H}$ & $\mathbf{T}$ & $\mathbf{A}$ & $\mathbf{E}$ & $\mathbf{E}$ & $\mathbf{K}$ & $\mathbf{A}$ & \\
\hline AY & 18 & 13 & 28 & 47 & 88 & 102 & 92 & 60 & 27 & 38 & 18 & 10 & 542 \\
\hline AOS & -8.4 & -7.7 & -0.5 & 5.7 & 10.3 & 14.0 & 17.1 & 17.3 & 13.1 & 7.0 & $\mathbf{0 . 0}$ & -6.4 & \\
\hline $\mathbf{E F}$ & 0.00 & 0.00 & 0.00 & 0.95 & 1.00 & 1.00 & 1.00 & 1.00 & 1.00 & 1.00 & 0.00 & 0.00 & \\
\hline YODY & $\mathbf{0}$ & $\mathbf{0}$ & $\mathbf{0}$ & 44 & 88 & 102 & 92 & 60 & 27 & 38 & $\mathbf{0}$ & $\mathbf{0}$ & 451 \\
\hline KODY & 18 & 13 & 28 & 3 & $\mathbf{0}$ & $\mathbf{0}$ & $\mathbf{0}$ & $\mathbf{0}$ & $\mathbf{0}$ & $\mathbf{0}$ & 18 & 10 & 90 \\
\hline KÖ & 46 & 59 & 88 & 5 & 0 & 0 & 0 & 0 & 0 & 0 & 18 & 27 & \\
\hline $\mathbf{K E}$ & 0 & 0 & $\mathbf{0}$ & 85 & 5 & 0 & 0 & 0 & 0 & 0 & $\mathbf{0}$ & $\mathbf{0}$ & 90 \\
\hline SG & 0 & 0 & 0 & 129 & 93 & 102 & 92 & 60 & 27 & 38 & 0 & 0 & 542 \\
\hline PET & 0 & 0 & 0 & 40 & 59 & 77 & 91 & 86 & 60 & 36 & 20 & 0 & 469 \\
\hline NSG & 0 & $\mathbf{0}$ & $\mathbf{0}$ & 90 & 34 & 25 & 1 & -26 & -34 & 2 & -20 & $\mathbf{0}$ & \\
\hline $\mathbf{T N}$ & 47 & 47 & 47 & 100 & 100 & 100 & 100 & 77 & 55 & 57 & 47 & 47 & \\
\hline$\wedge \mathrm{TN}$ & 0 & 0 & 0 & 53 & 0 & 0 & 0 & -23 & -22 & 2 & -10 & $\mathbf{0}$ & \\
\hline GET & 0 & 0 & 0 & 40 & 59 & 77 & 91 & 83 & 49 & 36 & 10 & 0 & 445 \\
\hline B\&A & 0 & 0 & 0 & 36 & 34 & 25 & 1 & $\mathbf{0}$ & $\mathbf{0}$ & $\mathbf{0}$ & 0 & 0 & 97 \\
\hline
\end{tabular}

*AOS ${ }^{0} \mathrm{C}$, diğer parametreler mm cinsindendir. 


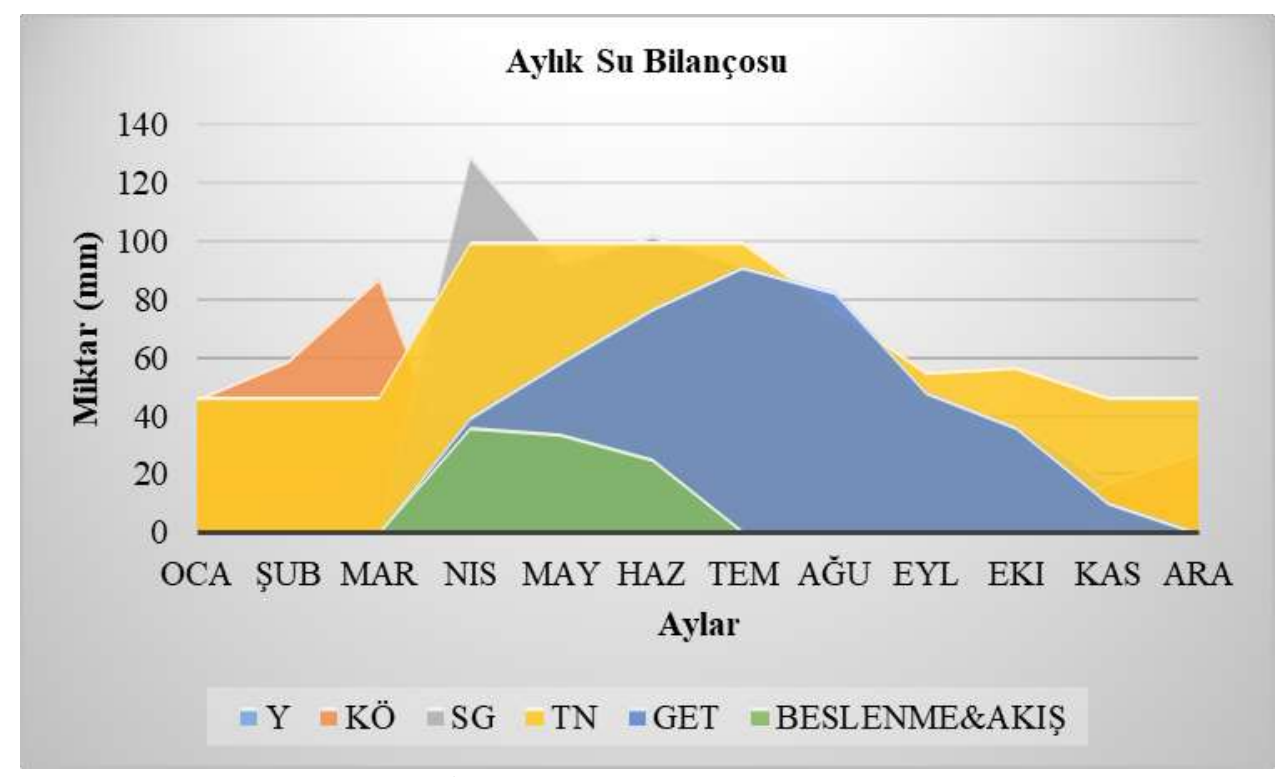

Şekil 6. Ardahan İli Thornthwaite tipi aylık su bilançosu grafiği

\subsection{Bingöl İli Su Bilançosu Sonuçları}

Tablo 6’ya göre Bingöl istasyonunda y1llık ortalama 727 mm yağış görülür. Kar örtüsü Aralık, Ocak ve Şubat aylarında oluşur. Kar erimesi ise Şubat ayında başlar ve Mart ayında maksimuma ulaşır. Mayıs ayından Ekim ayına kadar su açığı gözlemlenir. En yüksek PET Temmuz ayında meydana gelir. Toprak nemi Şubat, Mart ve Nisan aylarında maksimum kapasitededir. 2010-2018 y1lları arasında y1llık ortalama 283 mm yüzeysel akış meydana gelmiştir. Yağış PET'den küçüktür. Bingöl İli Thornthwaite tipi aylık su bilançosu grafiği Şekil 7'de görülmektedir.

Tablo 6. Bingöl İli Thornthwaite tipi su bilançosu tablosu

\begin{tabular}{|c|c|c|c|c|c|c|c|c|c|c|c|c|c|}
\hline \multirow[b]{2}{*}{ Parametre } & \multicolumn{12}{|c|}{ AYLAR } & \multirow[b]{2}{*}{ Yil } \\
\hline & $\mathbf{O}$ & Ş & $\mathbf{M}$ & $\mathbf{N}$ & $\mathbf{M}$ & $\mathbf{H}$ & $\mathbf{T}$ & $\mathbf{A}$ & $\mathbf{E}$ & $\mathbf{E}$ & $\mathbf{K}$ & A & \\
\hline $\mathbf{A Y}$ & 141 & 86 & 102 & 78 & 65 & 23 & 5 & 2 & 14 & 66 & 57 & 88 & 727 \\
\hline AOS & -0.8 & 1.3 & 6.4 & 12.2 & 16.5 & 22.6 & 27.2 & 27.3 & 22.0 & 14.5 & 7.4 & 1.9 & \\
\hline EF & 0.00 & 0.21 & 1.00 & 1.00 & 1.00 & 1.00 & 1.00 & 1.00 & 1.00 & 1.00 & 1.00 & 0.31 & \\
\hline YODY & $\mathbf{0}$ & 18 & 102 & 78 & 65 & 23 & 5 & 2 & 14 & 66 & 57 & 27 & 458 \\
\hline KODY & 141 & 68 & $\mathbf{0}$ & 0 & $\mathbf{0}$ & 0 & 0 & 0 & 0 & $\mathbf{0}$ & 0 & 61 & 269 \\
\hline KÖ & 183 & 198 & 0 & 0 & 0 & 0 & 0 & 0 & 0 & 0 & 0 & 42 & \\
\hline $\mathbf{K E}$ & $\mathbf{0}$ & 52 & 198 & $\mathbf{0}$ & 0 & 0 & 0 & 0 & 0 & 0 & 0 & 19 & 269 \\
\hline SG & 0 & 70 & 300 & 78 & 65 & 23 & 5 & 2 & 14 & 66 & 57 & 46 & 727 \\
\hline PET & 0 & 24 & 38 & 60 & 85 & 126 & 161 & 151 & 102 & 59 & 34 & 22 & 861 \\
\hline NSG & 0 & 47 & 262 & 18 & -20 & -103 & -155 & -149 & -88 & 8 & 24 & 24 & \\
\hline $\mathbf{T N}$ & 56 & 100 & 100 & 100 & 82 & 29 & 6 & 1 & 1 & 8 & 32 & 56 & \\
\hline$\Lambda T N$ & 0 & 44 & $\mathbf{0}$ & 0 & -18 & -53 & -23 & -5 & -1 & 8 & 24 & 24 & \\
\hline GET & 0 & 24 & 38 & 60 & 83 & 76 & 29 & 7 & 14 & 59 & 34 & 22 & 445 \\
\hline B\&A & 0 & 3 & 262 & 18 & 0 & 0 & 0 & 0 & 0 & 0 & 0 & 0 & 283 \\
\hline
\end{tabular}

*AOS ${ }^{0} \mathrm{C}$, diğer parametreler $\mathrm{mm}$ cinsindendir. 


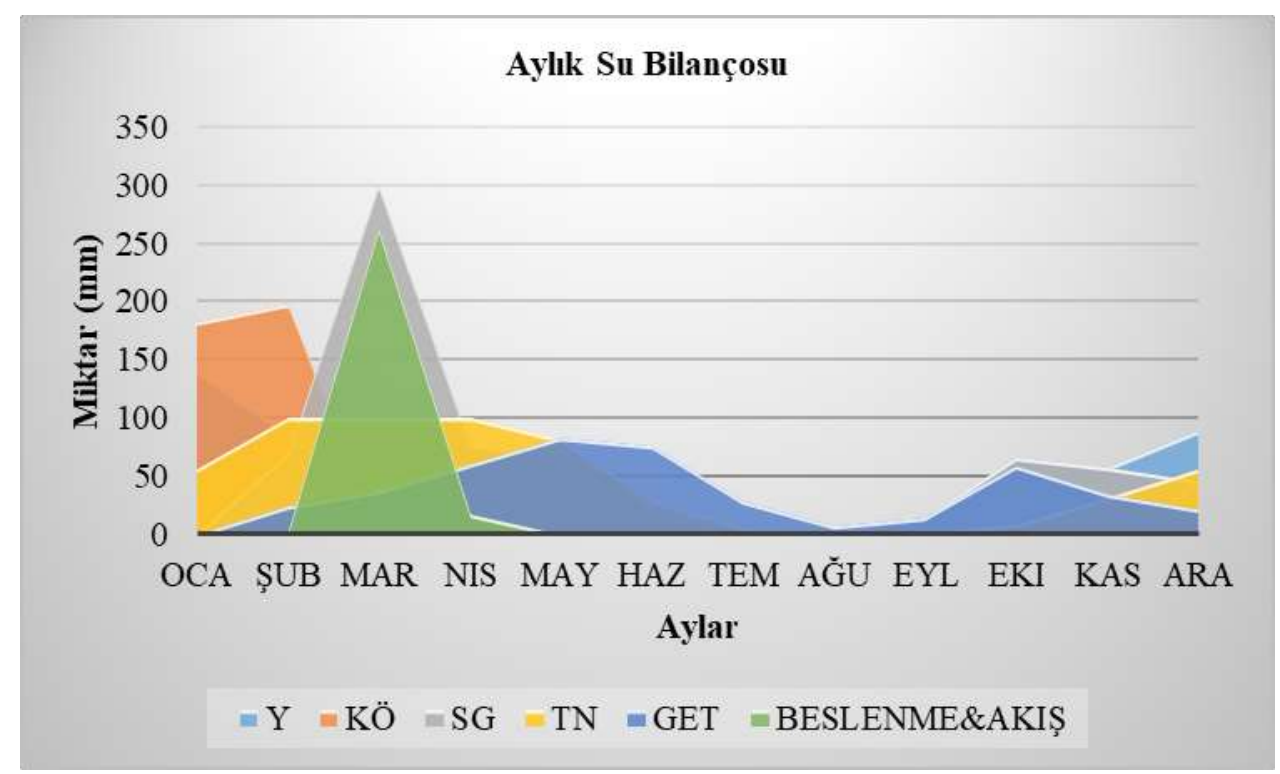

Şekil 7. Bingöl İli Thornthwaite tipi aylık su bilançosu grafiği

\subsection{Bitlis İli Su Bilançosu Sonuçları}

Tablo 7'ye göre çalı̧̧ma alanında en yüksek kar örtüsü miktarı Bitlis İli'ndedir. Kasım ve Mart ayları arasında kar örtüsü oluşur. Mart ve Nisan aylarında kar erimeleri gerçekleşir. Kasım ayından Mayıs ayına kadar toprak nemi maksimum kapasitededir. Haziran ve Eylül ayları arasında su açı̆̆ meydana gelir. Yağış PET'den büyüktür. 2010-2018 yılları arasında yıllık ortalama $561 \mathrm{~mm}$ yüzeysel akış meydana gelmiştir. Bitlis İli Thornthwaite tipi aylık su bilançosu grafiği Şekil 8'de görülmektedir.

Tablo 7. Bitlis İli Thornthwaite tipi su bilançosu tablosu

\begin{tabular}{|c|c|c|c|c|c|c|c|c|c|c|c|c|c|}
\hline \multirow[b]{2}{*}{ Parametre } & \multicolumn{12}{|c|}{ AYLAR } & \multirow[b]{2}{*}{ YII } \\
\hline & O & Ş & $\mathbf{M}$ & $\mathbf{N}$ & $\mathbf{M}$ & $\mathbf{H}$ & $\mathbf{T}$ & A & $\mathbf{E}$ & $\mathbf{E}$ & $\mathbf{K}$ & A & \\
\hline AY & 85 & 127 & 162 & 129 & 105 & 14 & 6 & 3 & 19 & 106 & 89 & 63 & 908 \\
\hline AOS & -4.6 & -3.2 & 1.0 & 7.3 & 12.1 & 17.9 & 22.9 & 23.0 & 18.0 & 10.6 & 3.7 & -3.0 & \\
\hline EF & 0.00 & 0.00 & 0.16 & 1.00 & 1.00 & 1.00 & 1.00 & 1.00 & 1.00 & 1.00 & 0.61 & 0.00 & \\
\hline YODY & 0 & 0 & 26 & 129 & 105 & 14 & 6 & 3 & 19 & 106 & 54 & 0 & 463 \\
\hline KODY & 85 & 127 & 136 & $\mathbf{0}$ & $\mathbf{0}$ & 0 & 0 & 0 & O & $\mathbf{0}$ & 35 & 63 & 446 \\
\hline KÖ & 162 & 289 & 356 & 0 & 0 & 0 & 0 & 0 & 0 & 0 & 14 & 77 & \\
\hline KE & $\mathbf{0}$ & $\mathbf{0}$ & 68 & 356 & 0 & 0 & 0 & 0 & 0 & 0 & 21 & 0 & 446 \\
\hline SG & 0 & 0 & 94 & 485 & 105 & 14 & 6 & 3 & 19 & 106 & 75 & 0 & 908 \\
\hline PET & 0 & 0 & 26 & 44 & 65 & 96 & 126 & 118 & 81 & 46 & 26 & 0 & 628 \\
\hline NSG & $\mathbf{0}$ & 0 & 68 & 441 & 41 & -81 & -119 & -115 & -62 & 60 & 49 & 0 & \\
\hline TN & 100 & 100 & 100 & 100 & 100 & 44 & 13 & 4 & 2 & 62 & 100 & 100 & \\
\hline$\Lambda \mathrm{TN}$ & 0 & 0 & 0 & 0 & 0 & -56 & -31 & -9 & -2 & 60 & 38 & 0 & \\
\hline GET & 0 & 0 & 26 & 44 & 65 & 70 & 37 & 12 & 21 & 46 & 26 & 0 & 348 \\
\hline B\&A & 0 & $\mathbf{0}$ & 68 & 441 & 41 & 0 & $\mathbf{0}$ & 0 & 0 & 0 & 11 & $\mathbf{0}$ & 561 \\
\hline
\end{tabular}

*AOS ${ }^{0} \mathrm{C}$, diğer parametreler mm cinsindendir. 


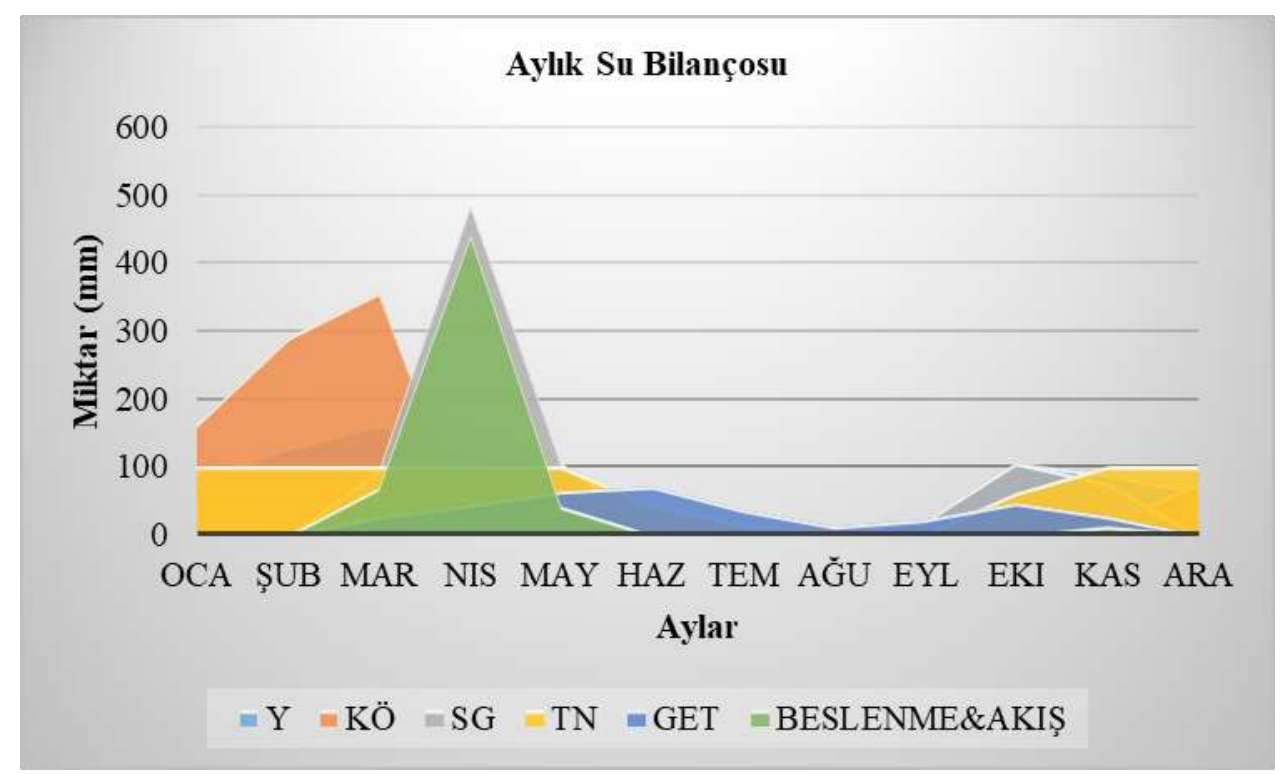

Şekil 8. Bitlis İli Thornthwaite tipi aylık su bilançosu grafiği

\subsection{Elazığ İli Su Bilançosu Sonuçları}

Tablo 8'e göre Elazığ istasyonunda su fazlası ya da yüzeysel akış oluşmamıştır. Kar örtüsü Aralık ve Şubat ayları arasında oluşur. Kar erimesi de Aralık ve Mart ayları arasında gerçekleşir. Toprak nemi 2010-2018 yılları arasında maksimum kapasite olan 100 mm'ye ulaşamamıştır. PET değeri neredeyse meydana gelen yağışın 3 katıdır. Şubat ve Mart ayları dışında su fazlası yoktur. Buradaki su fazlası da kar erimelerinden kaynaklanmaktadır.

Tablo 8. Elazığ İli Thornthwaite tipi su bilançosu tablosu

\begin{tabular}{|c|c|c|c|c|c|c|c|c|c|c|c|c|c|}
\hline \multirow[b]{2}{*}{ Parametre } & \multicolumn{12}{|c|}{ AYLAR } & \multirow[b]{2}{*}{ Yil } \\
\hline & $\mathbf{O}$ & Ş & $\mathbf{M}$ & $\mathbf{N}$ & $\mathbf{M}$ & $\mathbf{H}$ & $\mathbf{T}$ & A & $\mathbf{E}$ & $\mathbf{E}$ & $\mathbf{K}$ & $\mathbf{A}$ & \\
\hline AY & 35 & 41 & 39 & 43 & 55 & 10 & 2 & 0 & 8 & 32 & 33 & 33 & 331 \\
\hline AOS & 1.4 & 3.3 & 7.9 & 13.2 & 17.6 & 23.7 & 28.0 & 28.3 & 23.1 & 15.3 & 7.9 & 2.6 & \\
\hline EF & 0.23 & 0.55 & 1.00 & 1.00 & 1.00 & 1.00 & 1.00 & 1.00 & 1.00 & 1.00 & 1.00 & 0.43 & \\
\hline YODY & 8 & 23 & 39 & 43 & 55 & 10 & 2 & $\mathbf{0}$ & 8 & 32 & 33 & 14 & 267 \\
\hline KODY & 27 & 18 & 0 & $\mathbf{0}$ & $\mathbf{0}$ & 0 & 0 & 0 & 0 & 0 & 0 & 19 & 64 \\
\hline KÖ & 29 & 21 & 0 & 0 & 0 & 0 & 0 & 0 & 0 & 0 & 0 & 11 & \\
\hline $\mathbf{K E}$ & 9 & 26 & 21 & 0 & 0 & 0 & 0 & 0 & 0 & 0 & 0 & 8 & 64 \\
\hline SG & 17 & 49 & 60 & 43 & 55 & 10 & 2 & 0 & 8 & 32 & 33 & 22 & 331 \\
\hline PET & 22 & 27 & 41 & 64 & 90 & 135 & 168 & 160 & 109 & 62 & 35 & 23 & 936 \\
\hline NSG & -5 & 22 & 19 & -21 & -36 & -125 & -166 & -159 & -101 & -30 & -1 & -1 & \\
\hline TN & 0 & 22 & 41 & 33 & 23 & 7 & 1 & 0 & 0 & 0 & 0 & 0 & \\
\hline$\Lambda \mathrm{TN}$ & 0 & 22 & 19 & -8 & -10 & -16 & -5 & -1 & 0 & 0 & 0 & 0 & \\
\hline GET & 17 & 27 & 41 & 51 & 64 & 26 & 7 & 1 & 8 & 32 & 33 & 22 & 331 \\
\hline $\mathbf{B} \& \mathbf{A}$ & $\mathbf{0}$ & $\mathbf{0}$ & $\mathbf{0}$ & $\mathbf{0}$ & 0 & $\mathbf{0}$ & $\mathbf{0}$ & $\mathbf{0}$ & $\mathbf{0}$ & 0 & 0 & 0 & $\mathbf{0}$ \\
\hline
\end{tabular}

*AOS ${ }^{0} \mathrm{C}$, diğer parametreler $\mathrm{mm}$ cinsindendir. 


\subsection{Erzincan İli Su Bilançosu Sonuçları}

Tablo 9'a göre Erzincan istasyonunda da su fazlası ya da yüzeysel akış meydana gelmemiştir. En yüksek PET değeri Temmuz ayında görülmüştür. PET değeri yağıştan daha fazladır.

Tablo 9. Erzincan İli Thornthwaite tipi su bilançosu tablosu

\begin{tabular}{|c|c|c|c|c|c|c|c|c|c|c|c|c|c|}
\hline \multirow[b]{2}{*}{ Parametre } & \multicolumn{12}{|c|}{ AYLAR } & \multirow[b]{2}{*}{ Yll } \\
\hline & $\mathbf{O}$ & Ş & $\mathbf{M}$ & $\mathbf{N}$ & $\mathbf{M}$ & $\mathbf{H}$ & $\mathbf{T}$ & A & $\mathbf{E}$ & $\mathbf{E}$ & $\mathbf{K}$ & A & \\
\hline AY & 29 & 26 & 43 & 51 & 66 & 24 & 18 & 5 & 13 & 29 & 22 & 16 & 341 \\
\hline AOS & -0.9 & 1.4 & 6.5 & 11.9 & 15.9 & 20.9 & 25.0 & 25.5 & 20.5 & 12.9 & 6.0 & 1.0 & \\
\hline $\mathbf{E F}$ & 0.00 & 0.24 & 1.00 & 1.00 & 1.00 & 1.00 & 1.00 & 1.00 & 1.00 & 1.00 & 1.00 & 0.17 & \\
\hline YODY & $\mathbf{0}$ & 6 & 43 & 51 & 66 & 24 & 18 & 5 & 13 & 29 & 22 & 3 & 280 \\
\hline KODY & 29 & 20 & $\mathbf{0}$ & 0 & $\mathbf{0}$ & $\mathbf{0}$ & $\mathbf{0}$ & 0 & $\mathbf{0}$ & $\mathbf{0}$ & $\mathbf{0}$ & 13 & 61 \\
\hline Kö & 39 & 45 & 0 & 0 & 0 & 0 & 0 & 0 & 0 & 0 & 0 & 11 & \\
\hline $\mathbf{K E}$ & $\mathbf{0}$ & 14 & 45 & 0 & 0 & 0 & 0 & 0 & 0 & 0 & 0 & 2 & 61 \\
\hline SG & 0 & 20 & 88 & 51 & 66 & 24 & 18 & 5 & 13 & 29 & 22 & 5 & 341 \\
\hline PET & 0 & 24 & 38 & 59 & 82 & 115 & 143 & 137 & 94 & 53 & 30 & 20 & 796 \\
\hline NSG & 0 & -4 & 50 & -8 & -16 & -91 & -125 & -132 & -81 & -24 & -8 & -16 & \\
\hline TN & 0 & 0 & 51 & 47 & 40 & 16 & 5 & 1 & 1 & 0 & 0 & 0 & \\
\hline$\Lambda \mathrm{TN}$ & 0 & 0 & 50 & -4 & -7 & -24 & -11 & -3 & -1 & $\mathbf{0}$ & 0 & 0 & \\
\hline GET & 0 & 20 & 38 & 55 & 73 & 48 & 29 & 9 & 14 & 29 & 22 & 5 & 341 \\
\hline B\&A & 0 & 0 & 0 & 0 & 0 & 0 & 0 & 0 & 0 & 0 & 0 & 0 & 0 \\
\hline
\end{tabular}

*AOS ${ }^{0} \mathrm{C}$, diğer parametreler $\mathrm{mm}$ cinsindendir.

\subsection{Hakkâri İli Su Bilançosu Sonuçları}

Tablo 10. Hakkâri İli Thornthwaite tipi su bilançosu tablosu

\begin{tabular}{|c|c|c|c|c|c|c|c|c|c|c|c|c|c|}
\hline \multirow[b]{2}{*}{ Parametre } & \multicolumn{12}{|c|}{ AYLAR } & \multirow[b]{2}{*}{ Yll } \\
\hline & $\mathbf{O}$ & $\mathbf{S}$ & $\mathbf{M}$ & $\mathbf{N}$ & $\mathbf{M}$ & $\mathbf{H}$ & $\mathbf{T}$ & $\mathbf{A}$ & $\mathbf{E}$ & $\mathbf{E}$ & $\mathbf{K}$ & $\mathbf{A}$ & \\
\hline AY & 78 & 64 & 108 & 100 & 155 & 33 & 5 & 5 & 8 & 78 & 69 & 65 & 767 \\
\hline AOS & -2.6 & -0.7 & 4.5 & 10.1 & 15.0 & 21.1 & 25.8 & 25.9 & 21.3 & 13.3 & 6.2 & -0.5 & \\
\hline EF & 0.00 & 0.00 & 0.76 & 1.00 & 1.00 & 1.00 & 1.00 & 1.00 & 1.00 & 1.00 & 1.00 & 0.00 & \\
\hline YODY & $\mathbf{0}$ & 0 & 82 & 100 & 155 & 33 & 5 & 5 & 8 & 78 & 69 & $\mathbf{0}$ & 534 \\
\hline KODY & 78 & 64 & 26 & 0 & 0 & 0 & 0 & $\mathbf{0}$ & 0 & 0 & 0 & 65 & 233 \\
\hline KÖ & 143 & 206 & 56 & 0 & 0 & 0 & 0 & 0 & 0 & 0 & 0 & 65 & \\
\hline $\mathbf{K E}$ & $\mathbf{0}$ & $\mathbf{0}$ & 176 & 56 & $\mathbf{0}$ & $\mathbf{0}$ & 0 & $\mathbf{0}$ & $\mathbf{0}$ & $\mathbf{0}$ & 0 & $\mathbf{0}$ & 233 \\
\hline SG & 0 & 0 & 258 & 156 & 155 & 33 & 5 & 5 & 8 & 78 & 69 & 0 & 767 \\
\hline PET & $\mathbf{0}$ & $\mathbf{0}$ & 33 & 53 & 77 & 115 & 148 & 139 & 98 & 55 & 31 & $\mathbf{0}$ & 749 \\
\hline NSG & 0 & $\mathbf{0}$ & 225 & 104 & 78 & -82 & -143 & -134 & -90 & 24 & 37 & $\mathbf{0}$ & \\
\hline $\mathbf{T N}$ & 62 & 62 & 100 & 100 & 100 & 44 & 11 & 3 & 1 & 25 & 62 & 62 & \\
\hline$\Lambda \mathbf{T N}$ & 0 & 0 & 38 & 0 & 0 & -56 & -33 & -8 & -2 & 24 & 37 & 0 & \\
\hline GET & 0 & 0 & 33 & 53 & 77 & 89 & 38 & 13 & 9 & 55 & 31 & 0 & 399 \\
\hline $\mathbf{B \& A}$ & 0 & 0 & 187 & 104 & 78 & 0 & 0 & 0 & 0 & 0 & 0 & 0 & 368 \\
\hline
\end{tabular}

*AOS ${ }^{0} \mathrm{C}$, diğer parametreler $\mathrm{mm}$ cinsindendir. 
Tablo 10'a göre Hakkâri istasyonunda yıllık yağış miktarı hesap edilen Potansiyel Evapotranspirasyona göre fazladır. Mart, Nisan ve Mayıs aylarında toprak nemi maksimum kapasitededir. Kar erimeleri Mart ve Nisan aylarında meydana gelir. Haziran ve Eylül ayları arasında su açığı oluşur. Hakkâri İli Thornthwaite tipi aylık su bilançosu grafiği Şekil 9'da görülmektedir.

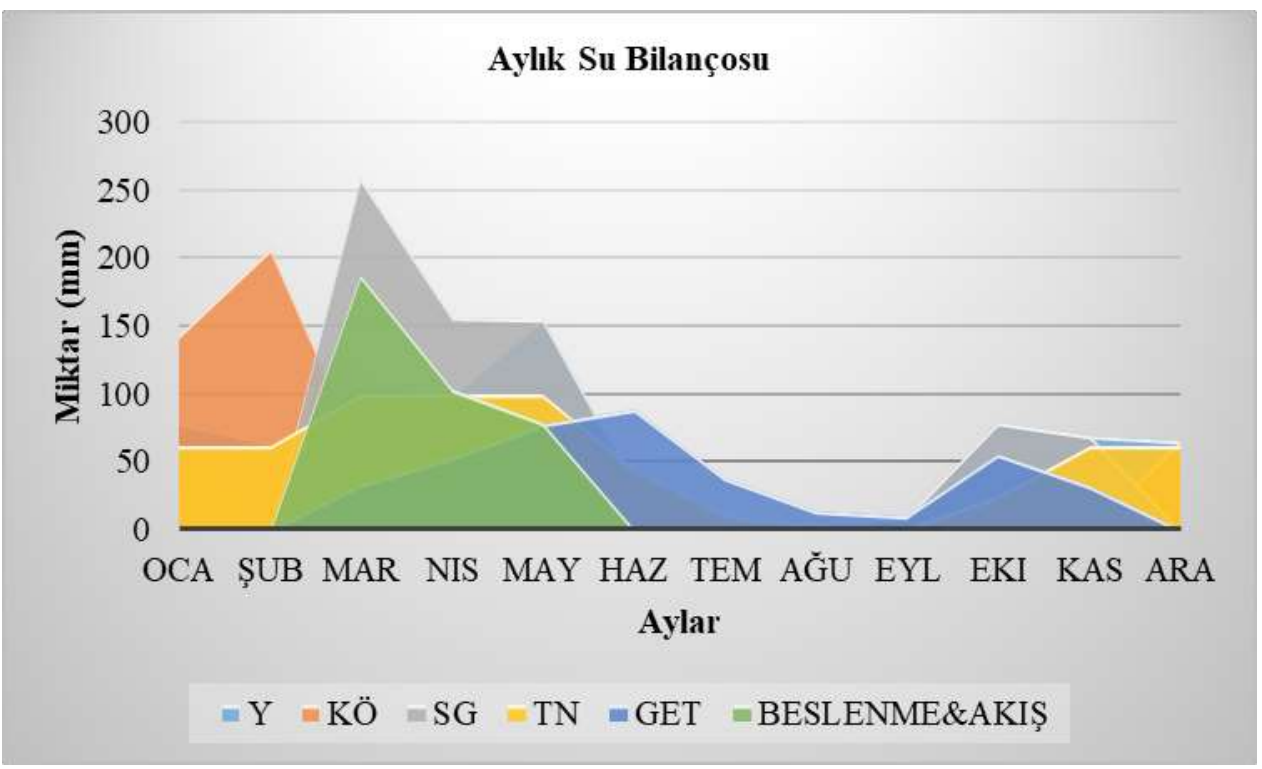

Şekil 9. Hakkâri İli Thornthwaite tipi aylık su bilançosu grafiği

\subsection{Iğdır İli Su Bilançosu Sonuçları}

Tablo 11'e göre Iğdır istasyonu çalışma alanında en düşük yağışın görüldügü istasyondur. Düşük yağışın yanında PET değerleri çok yüksektir. GET yıllık yağı̧̧ miktarıyla aynıdır. Şubat ayından Kasım ayına kadar su eksiği vardır. Kar erimeleri Şubat ve Mart ayında gerçekleşir. Temmuz ayında PET maksimuma ulaşmıştır.

Tablo 11. Iğdır İli Thornthwaite tipi su bilançosu tablosu

\begin{tabular}{|c|c|c|c|c|c|c|c|c|c|c|c|c|c|}
\hline \multirow[b]{2}{*}{ Parametre } & \multicolumn{12}{|c|}{ AYLAR } & \multirow[b]{2}{*}{ Yll } \\
\hline & $\mathbf{O}$ & Ş & $\mathbf{M}$ & $\mathbf{N}$ & $\mathbf{M}$ & $\mathbf{H}$ & $\mathbf{T}$ & $\mathbf{A}$ & $\mathbf{E}$ & $\mathbf{E}$ & $\mathbf{K}$ & $\mathbf{A}$ & \\
\hline AY & 10 & 12 & 9 & 35 & 49 & 26 & 13 & 8 & 9 & 33 & 19 & 10 & 233 \\
\hline AOS & -1.3 & 1.9 & 8.6 & 14.2 & 18.4 & 23.7 & 27.4 & 26.8 & 22.2 & 13.9 & 6.3 & -0.4 & \\
\hline EF & 0.00 & 0.31 & 1.00 & 1.00 & 1.00 & 1.00 & 1.00 & 1.00 & 1.00 & 1.00 & 1.00 & 0.00 & \\
\hline YODY & $\mathbf{0}$ & 4 & 9 & 35 & 49 & 26 & 13 & 8 & 9 & 33 & 19 & $\mathbf{0}$ & 205 \\
\hline KODY & 10 & 9 & $\mathbf{0}$ & $\mathbf{0}$ & $\mathbf{0}$ & $\mathbf{0}$ & $\mathbf{0}$ & $\mathbf{0}$ & $\mathbf{0}$ & $\mathbf{0}$ & $\mathbf{0}$ & 10 & 28 \\
\hline KÖ & 20 & 19 & 0 & 0 & 0 & 0 & 0 & 0 & 0 & 0 & 0 & 10 & \\
\hline $\mathbf{K E}$ & $\mathbf{0}$ & 9 & 19 & $\mathbf{0}$ & $\mathbf{0}$ & $\mathbf{0}$ & $\mathbf{0}$ & $\mathbf{0}$ & $\mathbf{0}$ & $\mathbf{0}$ & $\mathbf{0}$ & $\mathbf{0}$ & 28 \\
\hline SG & 0 & 13 & 28 & 35 & 49 & 26 & 13 & 8 & 9 & 33 & 19 & $\mathbf{0}$ & 233 \\
\hline PET & 0 & 25 & 43 & 69 & 96 & 136 & 164 & 148 & 104 & 56 & 31 & $\mathbf{0}$ & 870 \\
\hline NSG & $\mathbf{0}$ & -12 & -15 & -33 & -47 & -110 & -151 & -140 & -95 & -24 & -12 & $\mathbf{0}$ & \\
\hline $\mathbf{T N}$ & 0 & 0 & 0 & 0 & 0 & 0 & 0 & 0 & 0 & 0 & 0 & 0 & \\
\hline$\Lambda \mathrm{TN}$ & 0 & 0 & 0 & $\mathbf{0}$ & $\mathbf{0}$ & 0 & 0 & 0 & 0 & 0 & 0 & 0 & \\
\hline GET & 0 & 13 & 28 & 35 & 49 & 26 & 13 & 8 & 9 & 33 & 19 & 0 & 233 \\
\hline B\&A & 0 & 0 & 0 & 0 & 0 & 0 & 0 & 0 & 0 & 0 & 0 & 0 & 0 \\
\hline
\end{tabular}

*AOS ${ }^{0} \mathrm{C}$, diğer parametreler mm cinsindendir. 


\subsection{Kars İli Su Bilançosu Sonuçları}

Tablo 12'ye göre Kars istasyonunda yıllık 447 mm yağış görülür. Yağışın 84 mm'si kar olarak düşer. Yıllık PET değeri yıllık yağış değerinden daha fazladır. 2010-2018 yılları arasında ortalama $15 \mathrm{~mm}$ yüzeysel akış meydana gelmiştir. En yüksek PET Temmuz ayında görülür. Nisan ve Mayıs aylarında toprak nemi maksimum kapasitesine ulaşmıştır. Kars İli Thornthwaite tipi aylık su bilançosu grafiği Şekil 10'da görülmektedir.

Tablo 12. Kars İli Thornthwaite tipi su bilançosu tablosu

\begin{tabular}{|c|c|c|c|c|c|c|c|c|c|c|c|c|c|}
\hline \multirow[b]{2}{*}{ Parametre } & \multicolumn{12}{|c|}{ AYLAR } & \multirow[b]{2}{*}{ Yil } \\
\hline & O & Ş & $\mathbf{M}$ & $\mathbf{N}$ & $\mathbf{M}$ & $\mathbf{H}$ & $\mathbf{T}$ & $\mathbf{A}$ & $\mathbf{E}$ & $\mathbf{E}$ & $\mathbf{K}$ & $\mathbf{A}$ & \\
\hline AY & 17 & 14 & 26 & 32 & 73 & 58 & 67 & 47 & 25 & 59 & 14 & 14 & 447 \\
\hline AOS & -7.9 & -6.8 & 0.1 & 6.0 & 10.7 & 15.1 & 18.7 & 18.9 & 14.9 & 7.8 & 0.7 & -6.4 & \\
\hline EF & 0.00 & 0.00 & 0.01 & 1.00 & 1.00 & 1.00 & 1.00 & 1.00 & 1.00 & 1.00 & 0.12 & 0.00 & \\
\hline YODY & $\mathbf{0}$ & $\mathbf{0}$ & $\mathbf{0}$ & 32 & 73 & 58 & 67 & 47 & 25 & 59 & 2 & $\mathbf{0}$ & 363 \\
\hline KODY & 17 & 14 & 25 & $\mathbf{0}$ & 0 & $\mathbf{0}$ & $\mathbf{0}$ & $\mathbf{0}$ & 0 & $\mathbf{0}$ & 12 & 14 & 84 \\
\hline KÖ & 43 & 57 & 81 & 0 & 0 & 0 & 0 & 0 & 0 & 0 & 11 & 25 & \\
\hline KE & $\mathbf{0}$ & $\mathbf{0}$ & 1 & 81 & $\mathbf{0}$ & 0 & 0 & 0 & 0 & 0 & 2 & $\mathbf{0}$ & 84 \\
\hline SG & 0 & 0 & 1 & 113 & 73 & 58 & 67 & 47 & 25 & 59 & 3 & 0 & 447 \\
\hline PET & 0 & 0 & 24 & 41 & 60 & 82 & 100 & 94 & 67 & 38 & 21 & 0 & 528 \\
\hline NSG & 0 & $\mathbf{0}$ & -23 & 73 & 13 & -24 & -33 & -48 & -42 & 21 & -18 & $\mathbf{0}$ & \\
\hline TN & 37 & 37 & 29 & 100 & 100 & 78 & 56 & 35 & 23 & 44 & 37 & 37 & \\
\hline$\Lambda \mathrm{TN}$ & 0 & 0 & -8 & 71 & 0 & -22 & -22 & -21 & -12 & 21 & -7 & 0 & \\
\hline GET & 0 & 0 & 9 & 41 & 60 & 79 & 89 & 68 & 37 & 38 & 10 & 0 & 432 \\
\hline B\&A & 0 & 0 & 0 & 2 & 13 & 0 & 0 & 0 & 0 & 0 & 0 & 0 & 15 \\
\hline
\end{tabular}

*AOS ${ }^{0} \mathrm{C}$, diğer parametreler mm cinsindendir.

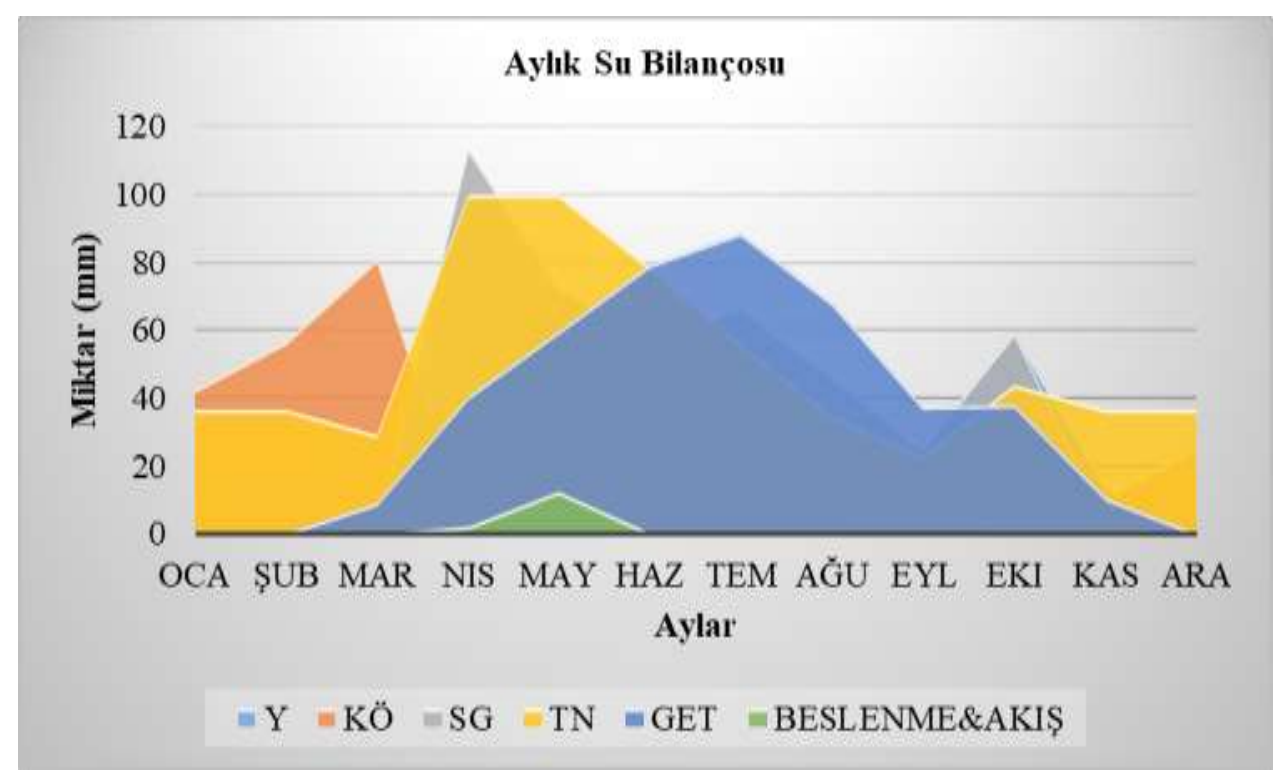

Şekil 10. Kars İli Thornthwaite tipi aylık su bilançosu grafiği 


\subsection{Malatya İli Su Bilançosu Sonuçları}

Tablo 13'e göre Malatya istasyonunda yüzeysel akış meydana gelmemiştir. Toprak nemi Şubat ayı dışında zemin rezervlerinden karşılanmaktadır.

Tablo 13. Malatya İli Thornthwaite tipi su bilançosu tablosu

\begin{tabular}{|c|c|c|c|c|c|c|c|c|c|c|c|c|c|}
\hline \multirow[b]{2}{*}{ Parametre } & \multicolumn{12}{|c|}{ AYLAR } & \multirow[b]{2}{*}{ Yll } \\
\hline & $\mathbf{O}$ & $\mathbf{S}$ & $\mathbf{M}$ & $\mathbf{N}$ & $\mathbf{M}$ & $\mathbf{H}$ & $\mathbf{T}$ & $\mathbf{A}$ & $\mathbf{E}$ & $\mathbf{E}$ & $\mathbf{K}$ & $\mathbf{A}$ & \\
\hline AY & 33 & 46 & 33 & 35 & 41 & 7 & 4 & 3 & 11 & 42 & 30 & 30 & 313 \\
\hline AOS & 1.6 & 4.2 & 8.8 & 14.2 & 18.4 & 24.4 & 28.7 & 29.1 & 24.2 & 15.9 & 8.7 & 3.1 & \\
\hline EF & 0.27 & 0.70 & 1.00 & 1.00 & 1.00 & 1.00 & 1.00 & 1.00 & 1.00 & 1.00 & 1.00 & 0.52 & \\
\hline YODY & 9 & 32 & 33 & 35 & 41 & 7 & 4 & 3 & 11 & 42 & 30 & 16 & 261 \\
\hline KODY & 24 & 14 & 0 & 0 & $\mathbf{0}$ & $\mathbf{0}$ & $\mathbf{0}$ & $\mathbf{0}$ & $\mathbf{0}$ & $\mathbf{0}$ & $\mathbf{0}$ & 14 & 52 \\
\hline KÖ & 23 & 11 & 0 & 0 & 0 & 0 & 0 & 0 & 0 & 0 & 0 & 7 & \\
\hline $\mathbf{K E}$ & 8 & 25 & 11 & $\mathbf{0}$ & 0 & 0 & 0 & 0 & 0 & 0 & 0 & 7 & 52 \\
\hline SG & 17 & 57 & 44 & 35 & 41 & 7 & 4 & 3 & 11 & 42 & 30 & 23 & 313 \\
\hline PET & 22 & 29 & 44 & 68 & 95 & 139 & 174 & 166 & 116 & 64 & 37 & 24 & 977 \\
\hline NSG & -5 & 28 & $\mathbf{0}$ & -33 & -54 & -132 & -170 & -164 & -105 & -22 & -7 & -1 & \\
\hline TN & 0 & 28 & 28 & 20 & 12 & 3 & 1 & 0 & 0 & 0 & 0 & 0 & \\
\hline$\Lambda \mathrm{TN}$ & 0 & 28 & 0 & -8 & -8 & -9 & -3 & 0 & 0 & 0 & 0 & 0 & \\
\hline GET & 17 & 29 & 44 & 43 & 50 & 16 & 6 & 3 & 11 & 42 & 30 & 23 & 313 \\
\hline $\mathbf{B} \& \mathbf{A}$ & 0 & 0 & 0 & 0 & 0 & 0 & 0 & 0 & 0 & 0 & 0 & 0 & 0 \\
\hline
\end{tabular}

*AOS ${ }^{0} \mathrm{C}$, diğer parametreler mm cinsindendir.

\subsection{Muş İli Su Bilançosu Sonuçları}

Tablo 14. Muş İli Thornthwaite tipi su bilançosu tablosu

\begin{tabular}{|c|c|c|c|c|c|c|c|c|c|c|c|c|c|}
\hline \multirow[b]{2}{*}{ Parametre } & \multicolumn{12}{|c|}{ AYLAR } & \multirow[b]{2}{*}{ Yll } \\
\hline & $\mathbf{O}$ & $\mathbf{S}$ & $\mathbf{M}$ & $\mathbf{N}$ & $\mathbf{M}$ & $\mathbf{H}$ & $\mathbf{T}$ & $\mathbf{A}$ & $\mathbf{E}$ & $\mathbf{E}$ & $\mathbf{K}$ & $\mathbf{A}$ & \\
\hline AY & 81 & 72 & 92 & 51 & 66 & 26 & 9 & 2 & 13 & 68 & 44 & 56 & 581 \\
\hline AOS & -4.7 & -3.0 & 4.0 & 10.7 & 15.2 & 21.0 & 26.2 & 26.5 & 21.5 & 13.4 & 5.5 & -1.9 & \\
\hline EF & 0.00 & 0.00 & 0.66 & 1.00 & 1.00 & 1.00 & 1.00 & 1.00 & 1.00 & 1.00 & 0.92 & 0.00 & \\
\hline YODY & $\mathbf{0}$ & $\mathbf{0}$ & 61 & 51 & 66 & 26 & 9 & 2 & 13 & 68 & 41 & $\mathbf{0}$ & 338 \\
\hline KODY & 81 & 72 & 31 & $\mathbf{0}$ & $\mathbf{0}$ & $\mathbf{0}$ & 0 & 0 & $\mathbf{0}$ & $\mathbf{0}$ & 3 & 56 & 243 \\
\hline KÖ & 137 & 210 & 81 & 0 & 0 & 0 & 0 & 0 & 0 & 0 & 0 & 56 & \\
\hline $\mathbf{K E}$ & $\mathbf{0}$ & $\mathbf{0}$ & 160 & 81 & $\mathbf{0}$ & $\mathbf{0}$ & 0 & $\mathbf{0}$ & $\mathbf{0}$ & $\mathbf{0}$ & 3 & $\mathbf{0}$ & 243 \\
\hline SG & 0 & 0 & 221 & 132 & 66 & 26 & 9 & 2 & 13 & 68 & 44 & 0 & 581 \\
\hline PET & 0 & $\mathbf{0}$ & 32 & 55 & 79 & 115 & 152 & 144 & 99 & 55 & 30 & 0 & 761 \\
\hline NSG & $\mathbf{0}$ & $\mathbf{0}$ & 189 & 77 & -13 & -89 & -143 & -142 & -87 & 14 & 14 & $\mathbf{0}$ & \\
\hline $\mathbf{T N}$ & 29 & 29 & 100 & 100 & 88 & 36 & 9 & 2 & 1 & 14 & 29 & 29 & \\
\hline$\Lambda \mathbf{T N}$ & $\mathbf{0}$ & $\mathbf{0}$ & 71 & $\mathbf{0}$ & -12 & -52 & -28 & -7 & -1 & 14 & 14 & $\mathbf{0}$ & \\
\hline GET & 0 & 0 & 32 & 55 & 78 & 78 & 37 & 9 & 14 & 55 & 30 & 0 & 387 \\
\hline B\&A & 0 & 0 & 117 & 77 & $\mathbf{0}$ & 0 & 0 & 0 & $\mathbf{0}$ & 0 & 0 & $\mathbf{0}$ & 194 \\
\hline
\end{tabular}

*AOS ${ }^{0} \mathrm{C}$, diğer parametreler mm cinsindendir. 
Tablo 14'e göre Muş istasyonunda en fazla kar örtüsü Şubat ayında oluşur. Yüzeysel akış en fazla Mart ayında görülür. Mart ve Nisan aylarında toprak nemi maksimuma ulaşır. Muş İli Thornthwaite tipi aylık su bilançosu grafiği Şekil 11'de görülmektedir.

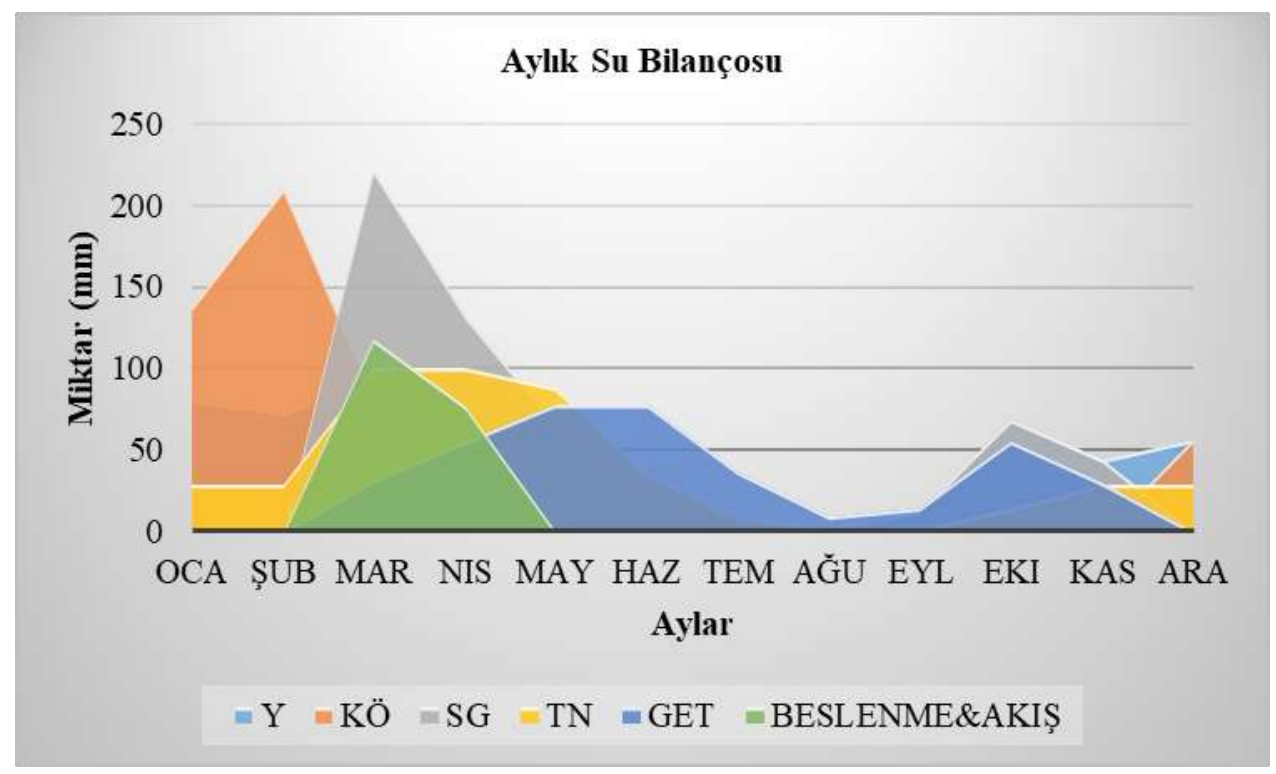

Şekil 11. Muş İli Thornthwaite tipi aylık su bilançosu grafiği

\subsection{Tunceli İli Su Bilançosu Sonuçları}

Tablo 15'e göre Tunceli istasyonunda $244 \mathrm{~mm}$ yüzeysel akış meydana gelmiştir. PET değeri yağış değerinden daha fazladır. En fazla su girdisi Mart ayında görülür. En fazla su açığı Ağustos ayında meydana gelir. Tunceli İli Thornthwaite tipi aylık su bilançosu grafiği Şekil 12'de görülmektedir.

Tablo 15. Tunceli İli Thornthwaite tipi su bilançosu tablosu

\begin{tabular}{|c|c|c|c|c|c|c|c|c|c|c|c|c|c|}
\hline & \multicolumn{10}{|c|}{ AYLAR } \\
\hline Parametre & O & S & M & N & M & H & T & A & E & E & K & A & YIl \\
\hline AY & 149 & 82 & 87 & 75 & 65 & 11 & 22 & 3 & 13 & 52 & 48 & 103 & 709 \\
\hline AOS & 0.2 & 2.4 & 7.4 & 12.8 & 16.8 & 22.9 & 27.5 & 27.8 & 22.3 & 14.7 & 7.4 & 1.7 & \\
\hline EF & 0.04 & 0.40 & 1.00 & 1.00 & 1.00 & 1.00 & 1.00 & 1.00 & 1.00 & 1.00 & 1.00 & 0.28 & \\
\hline YODY & 6 & 33 & 87 & 75 & 65 & 11 & 22 & 3 & 13 & 52 & 48 & 28 & 442 \\
\hline KODY & 143 & 49 & 0 & 0 & 0 & 0 & 0 & 0 & 0 & 0 & 0 & 74 & 266 \\
\hline KÖ & 189 & 142 & 0 & 0 & 0 & 0 & 0 & 0 & 0 & 0 & 0 & 54 & \\
\hline KE & 8 & 96 & 142 & 0 & 0 & 0 & 0 & 0 & 0 & 0 & 0 & 21 & 266 \\
\hline SG & 14 & 128 & 229 & 75 & 65 & 11 & 22 & 3 & 13 & 52 & 48 & 49 & 709 \\
\hline PET & 20 & 26 & 40 & 62 & 87 & 128 & 163 & 156 & 104 & 59 & 33 & 21 & 901 \\
\hline NSG & -6 & 103 & 189 & 12 & -22 & -117 & -141 & -152 & -91 & -7 & 14 & 27 & \\
\hline TN & 40 & 100 & 100 & 100 & 80 & 25 & 6 & 1 & 1 & 0 & 15 & 42 & \\
\hline$\Lambda$ TN & -2 & 60 & 0 & 0 & -20 & -55 & -19 & -5 & -1 & 0 & 14 & 27 & \\
\hline GET & 17 & 26 & 40 & 62 & 84 & 67 & 41 & 8 & 13 & 52 & 33 & 21 & 465 \\
\hline B\&A & 0 & 42 & 189 & 12 & 0 & 0 & 0 & 0 & 0 & 0 & 0 & 0 & 244 \\
\hline
\end{tabular}

*AOS ${ }^{0} \mathrm{C}$, diğer parametreler $\mathrm{mm}$ cinsindendir. 


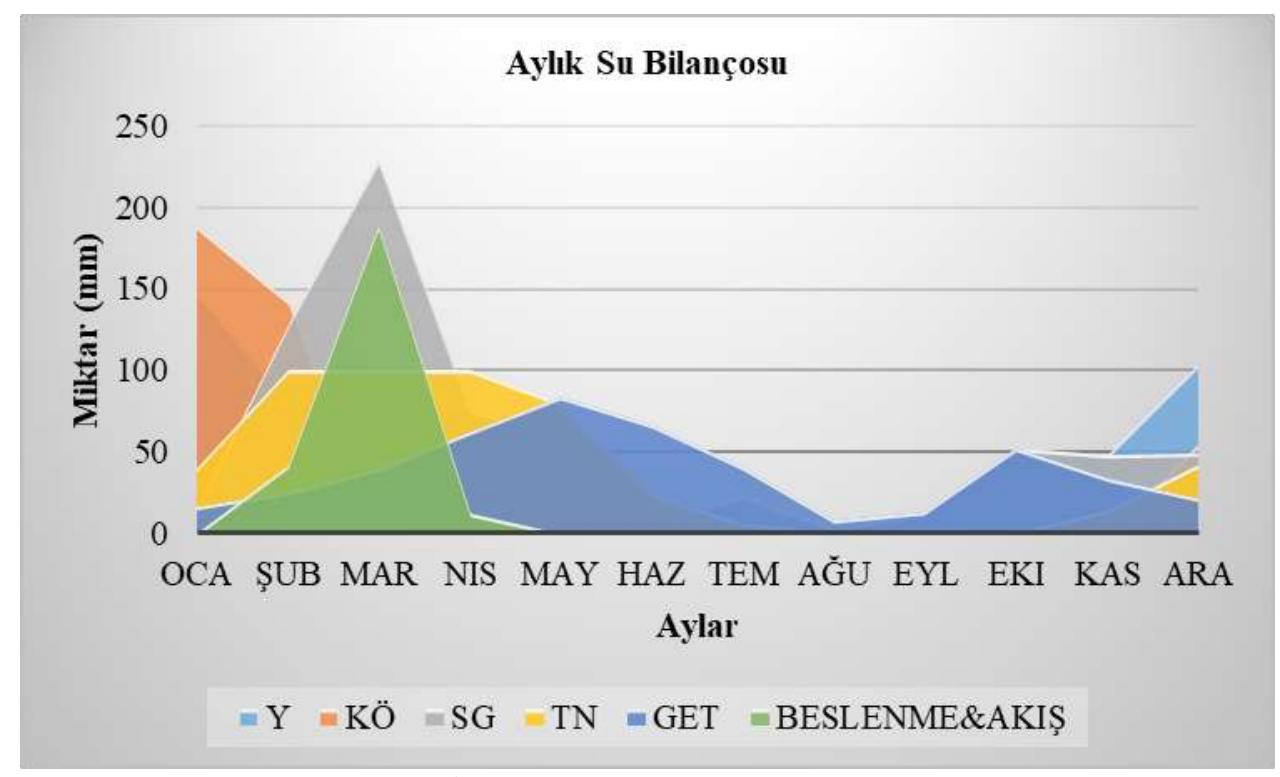

Şekil 12. Tunceli İli Thornthwaite tipi aylık su bilançosu grafiği

\subsection{Van İli Su Bilançosu Sonuçları}

Tablo 16'ya göre Van istasyonunda sadece Nisan ayında toprak nemi maksimum kapasitesine ulaşmıștır. PET değeri yıllık yağış değerinden daha fazladır. En fazla su açı̆̆ı Temmuz ayında meydana gelir. 363 mm yıllık yağışın 103 mm'si kar olarak düşer. Toprak nemindeki azalış en çok Haziran ayında oluşur.

Tablo 16. Van İli Thornthwaite tipi su bilançosu tablosu

\begin{tabular}{|c|c|c|c|c|c|c|c|c|c|c|c|c|c|}
\hline & \multicolumn{10}{|c|}{ AYLAR } \\
\hline Parametre & O & S & M & N & M & H & T & A & E & E & K & A & YIl \\
\hline AY & 38 & 20 & 38 & 54 & 52 & 18 & 3 & 4 & 15 & 61 & 28 & 30 & 363 \\
\hline AOS & -1.2 & -0.2 & 3.9 & 9.3 & 13.8 & 19.2 & 23.3 & 23.5 & 18.9 & 11.9 & 5.2 & 0.6 & \\
\hline EF & 0.00 & 0.00 & 0.65 & 1.00 & 1.00 & 1.00 & 1.00 & 1.00 & 1.00 & 1.00 & 0.86 & 0.11 & \\
\hline YODY & 0 & 0 & 25 & 54 & 52 & 18 & 3 & 4 & 15 & 61 & 24 & 3 & 260 \\
\hline KODY & 38 & 20 & 14 & 0 & 0 & 0 & 0 & 0 & 0 & 0 & 4 & 27 & 103 \\
\hline KÖ & 63 & 83 & 34 & 0 & 0 & 0 & 0 & 0 & 0 & 0 & 1 & 25 & \\
\hline KE & 0 & 0 & 63 & 34 & 0 & 0 & 0 & 0 & 0 & 0 & 3 & 3 & 103 \\
\hline SG & 0 & 0 & 87 & 88 & 52 & 18 & 3 & 4 & 15 & 61 & 28 & 6 & 363 \\
\hline PET & 0 & 0 & 32 & 50 & 72 & 104 & 129 & 122 & 85 & 50 & 29 & 20 & 693 \\
\hline NSG & 0 & 0 & 56 & 38 & -20 & -86 & -126 & -117 & -71 & 11 & -2 & -14 & \\
\hline TN & 11 & 11 & 67 & 100 & 82 & 35 & 10 & 3 & 2 & 13 & 13 & 11 & \\
\hline NTN & 0 & 0 & 56 & 33 & -18 & -47 & -25 & -7 & -2 & 11 & 0 & -2 & \\
\hline GET & 0 & 0 & 32 & 50 & 70 & 65 & 28 & 11 & 16 & 50 & 28 & 8 & 358 \\
\hline B\&A & 0 & 0 & 0 & 5 & 0 & 0 & 0 & 0 & 0 & 0 & 0 & 0 & 5 \\
\hline
\end{tabular}

*AOS ${ }^{0} \mathrm{C}$, diğer parametreler mm cinsindendir.

\section{Sonuç ve Öneriler}

Su bulunabilirliği, 21. yüzyılda önemli bir husus haline gelmektedir. Su bilançoları, su kullanıcılarının ve yöneticilerinin hidrolojik çevrimi ölçmek için kullandıkları araçlardır. Bir su bilançosu, su hareketi oranlarının ve atmosferin, arazi yüzeyinin ve yeraltı yüzeyinin tamamının veya bir kısmındaki su 
deposundaki değişimin bir muhasebesidir. Kavram olarak basit olmasına rağmen, su bilançolarının doğru bir şekilde belirlenmesi zor olabilir. Bu çalışmada da Doğu Anadolu Bölgesi'nde Thornthwaite tipi aylık su bilançosu hazırlanmıştır. Bu bölge hidrolojik çevrimin bütün parametrelerini içermektedir. Özellikle kar parametresi bu bölgede diğer bölgelere göre daha fazla önem kazanmaktadır. Çünkü kar donmuş halde uzun süre toprak üzerinde kaldığından dolayı önemli bir diğer parametre olan yüzeysel akış1 etkilemektedir. Çalışma bölgesinde 13 meteoroloji istasyonunda yapılan analiz sonuçlarına göre bölgede özellikle Temmuz ayında PET değerleri maksimuma ulaşmaktadır. Karasal iklimin egemen olduğu bölgede Elazığ, Erzincan, Iğdır ve Malatya'da su kaynaklarını besleyecek yüzeysel akışın olmadığı ortaya çıkmıştır. Karın daha çok yağdığı bölgelerde örneğin Bitlis istasyonunda yüzeysel akış da fazla meydana gelmiştir. Yüzeysel akış su kaynaklarını beslediğinden dolayı bu tip çalışmalar göz önüne alınmalıdır. Halkın ve karar vericilerin, su bilançolarındaki belirsizliklerin ve bu belirsizliklerin insan ve çevre ihtiyaçları için ne kadar su kullanabileceğinin değerlendirilmesindeki göreceli önemini takdir etmesi önemlidir.

\section{Kaynaklar}

[1] Moghaddam E.T., Mohammadkhan S. 2017. An Estimation of Thornthwaite Monthly WaterBalance in Mighan Sub-Basin. Natural Environment Change, Winter \& Spring, 3 (1): 71-80.

[2] Dönmez S. 2018. Akşehir Gölü’ndeki Su Çekilmesinin Meteorolojik ve Uydu Verileri ile Incelenmesi. Journal of the Faculty of Engineering and Architecture of Gazi University, 33 (1): $177-188$.

[3] Lutz A.J. 2009. The Water Balance of the Okanogan River Watershed in the United States, The Okanogan Conservation District 1251 South Second Avenue Okanogan, WA 98840.

[4] McCabe G.J., Markstrom S.L. 2017. A monthly water-balance model driven by a graphical user interface, U.S.Geological Survey Open-File report 6 p.

[5] Thornthwaite C.W., Mather J.R. 1955. The Water Balance. Publications in Climatology 8.

[6] Vörösmarty C.J., Federer C.A., Schloss A.L. 1998. Evaporation functions compared on US watersheds: possible implications for global-scale water balance and terrestrial ecosystem modeling, Journal of Hydrology, 207:147-169.

[7] Google Earth Pro Version 7.3. 2018. Eastern Anatolia Region, Turkey. NOAA, DigitalGlobe 2018, https://www.google.com/earth/download/gep/agree.html. (Erişim tarihi: 20.12.2018).

[8] Hamon W.R. 1963. Computation of direct runoff amounts from storm rainfall. International Association of Scientific Hydrology Publication, 63:52-62.

[9] Dingman S.L. 2002. Physical Hydrology. Prentice Hall, Upper Saddle River, NJ. 